Author manuscript

Aquat Ecol. Author manuscript; available in PMC 2021 October 27.

About author manuscripts

Submit a manuscript

Published in final edited form as:

Aquat Ecol. 2021 September 12; 0: . doi:10.1007/s10452-021-09900-2.

\title{
Macroinvertebrates at the source: flow duration and seasonality drive biodiversity and trait composition in rheocrene springs of the Western Allegheny Plateau, USA
}

\author{
Gregory J. Pond, Kelly J. G. Krock, Leah F. Ettema \\ U.S. EPA Region 3, Laboratory Services and Applied Science Division, Field Services Branch \\ 1060 Chapline St., Wheeling, WV 26003, USA
}

\begin{abstract}
Documenting flow regimes and the ecology of source headwater streams has gained considerable attention for scientific and regulatory purposes. These streams do not appear on standard maps, and local physiographic and climatologic conditions can control their origins. We investigated macroinvertebrate assemblages seasonally and in relation to flow duration, catchment and habitat variables within 14 source headwaters $(<1 \mathrm{ha})$ in the Western Allegheny Plateau over a 19-month period. We classified 6 perennial $(P)$ and 8 intermittent $(I)$ streams directly with continuous flow data loggers. Several biological and trait-based metrics could distinguish flow class, but few instream physical measures could. Macroinvertebrate metrics and assemblage dispersion varied seasonally and responded significantly along a gradient of total flow duration. Separate indicator species analyses generated 22 genera and 15 families with significant affinities to $P$ streams. Richness of $P$-indicator taxa was also strongly correlated with flow duration gradients, and we estimated a total flow duration changepoint at $77 \%$ ( 3 indicator families) followed by a sharp increase in richness. Two rapid field-based flow duration methods (NC Stream Identification index and $\mathrm{OH}$ Headwater Habitat Evaluation index) could distinguish upstream ephemeral reaches from $P$ and $I$ reaches, but misclassified $P$ as $I$ more frequently. Our findings highlight that diverse coldwater macroinvertebrate assemblages inhabited extremely small, low-discharge springs in the region, and responded with flow duration. These source headwater habitats are susceptible to human disturbance and should be monitored as is routinely done in larger lotic systems.
\end{abstract}

\section{Keywords}

Headwater streams; Intermittent streams; Flow permanence; Indicators

\footnotetext{
$\bowtie$ Pond.greg@epa.gov.

Author's contribution All authors contributed to the study conception, design, sampling, and analysis. The first draft of the manuscript was written by GJP, and all authors commented on previous versions of the manuscript. All authors read and approved the final manuscript.

Conflict of interest The authors have no conflicts of interest or financial disclosures to declare that are relevant to the content of this article.

Supplementary Information The online version contains supplementary material available at https://doi.org/10.1007/ s10452-021-09900-2.
} 


\section{Introduction}

Assessing hydrological and ecological relationships in headwaters springs is critical for both conservation and regulatory purposes. Although headwater stream research has advanced considerably, source headwaters (upland linear seeps and springs not delineated on maps) are still poorly studied. Headwater streams contribute to the health and functioning of downstream waterbodies (e.g., MacDonald and Coe 2007; Meyer et al. 2007; Wipfli et al. 2007; Williams 2016; Liebowitz et al. 2018) and represent disproportionately high biodiversity to stream networks (Finn et al. 2011). Despite this evidence, the biodiversity, function, and health of these systems remain at risk from disturbances associated with many forms of upland development. Accordingly, there exists an urgent need to monitor these systems and our study aimed to acquire further ecological insights on headwater streams at risk which is vital for protecting and restoring them. While state and federal environmental agencies are responsible for ensuring that regulated activities maintain stream health, small headwater streams are sometimes overlooked in land use planning and resource conservation (Bishop et al. 2008). Moreover, many environmental resource agencies do not monitor small rheocrene springs (water quality or biology), yet applicants for water-related activities are often required to assess them.

The US Clean Water Act (CWA) requires that aquatic life uses (ALUs) and functions must be maintained or restored in waterbodies that are deemed jurisdictional. Discharge of dredge and fill materials or chemical pollutants must comply with water quality criteria to protect ALUs. Since stream flow duration class (ephemeral $(E)$, intermittent $(I)$, and perennial $(P)$ ) can influence permitting decisions to avoid, minimize, compensate for loss, or to apply wasteload allocations, proper characterization of headwater streams is necessary to achieve the goals of the CWA. Definitions of flow regimes are varied in the scientific literature and in regulatory applications. Narratively, $E$ channels flow only during and immediately following precipitation or snowmelt (Fritz et al. 2006), while $I$ channels are typically defined as having continuous surface flow for part of the year (from runoff, snowmelt, and groundwater contributions). $P$ channels typically have continuous surface flow throughout the year except during drought (Fritz et al. 2006). Fritz et al. (2020) provided an extensive review and framework for developing rapid stream flow duration methodology that are relevant to CWA programs.

The flow origins of linear seeps and rheocrene springs can be spatially variable, where channels longitudinally expand and contract based on prevailing precipitation patterns, groundwater levels, and natural erosion and deposition (Wigington et al. 2005; Wohls 2017). The point where water emanates from the ground can vary with (1) local microtopography shaped by past episodic landslides (e.g., location and magnitude of rotational slumping and hummock formation), (2) the underlying lithological fracturing of the confining aquitard below, and (3) soil heterogeneity and porosity (Shultz 1988; Cook 2008). In some physiographic areas, stream origins might flow continuously for hundreds of meters and then disappear, flowing within shallow subsurface zones under colluvial and organic materials (e.g., Gooderham et al. 2007; Jensen et al. 2019). These shallow subsurface habitats still harbor diverse invertebrate assemblages that resemble surface assemblages (Griffith and Perry 1993; Collins et al. 2007; Dole-Olivier 2011). This hyporheic habitat 
plays a major role in the life cycle of benthic macroinvertebrates, particularly as refugia for aquatic organisms during low-flow periods (Griffith and Perry 1993; Hose et al. 2005; Stubbington et al. 2017).

Since long-term flow duration studies do not often fit into the timeline of the CWA permitting process, obligate aquatic organisms such as macroinvertebrates, as well as other biological (e.g., salamanders, Johnson et al. 2009; bryophytes, Fritz et al. 2009) and physical indicators (e.g., Fritz et al. 2008, 2013), provide critical evidence of the prevailing flow regime. In Central Europe, Straka et al. (2019) developed a macroinvertebrate multimetric tool that discriminated flow classes and detected antecedent drying events. These studies exemplify that aquatic organisms should be considered in short-term studies of flow duration because of their relatively long lifespans, where their presence can indicate antecedent conditions as well. Benthic macroinvertebrates make up a key organism group in headwaters, but community structure can vary across spatiotemporal (e.g., longitudinal, seasonal, flow duration) and habitat factors (Feminella 1996; Finn et al. 2011). Deterministic factors such as habitat and landscape filters, stream size and network position, and seasonality (e.g., Poff 1997; Brown and Swan 2010; Finn et al. 2011; Lehotský et al. 2016) can serve as drivers of assemblage structure and trait composition, and thus, further studies are needed to improve our ability to characterize these relationships.

Our primary objectives were to quantify flow duration and physical characteristics at stream origins and to relate these variables to macroinvertebrate community structure among potential flow classes. We assessed common taxonomic and trait-based metrics and a regional bioassessment index for discriminating flow classes. We predicted that shifts in macroinvertebrate diversity and community structure would be evident between wet and dry seasons but also be tied strongly to a gradient of flow duration. Lastly, we provide recommendations for indicators in determining flow classes in source headwater streams in the study region.

\section{Methods}

\section{Study area}

Our study sites encompassed portions of northern West Virginia and southeastern Ohio and lie within the unglaciated Permian Hills subecoregion of the Western Allegheny Plateau (Woods et al. 1996) (Fig. 1). We studied 14 high-gradient forested springs (> 80\% forest of $\sim 25-75$-yr-old temperate central hardwood and mixed mesophytic vegetation) clustered among 5 distinct areas (2-3 sites per area). Site nesting was necessary to access different public lands spanning the ecoregion and not for statistical purposes. These nonkarst springs emerge between 300 and $400 \mathrm{~m}$ asl and are all circumneutral tributaries of the Ohio River. Evapotranspiration exceeds precipitation in June-September across the region (dry season), whereas full plant dormancy extends from November to May (wet season). The study region lies within the humid continental-hot summer Köppen-Geiger climate classification (Dfa; Peel et al. 2007). Steep terrain in the uplands coupled with cobble-boulder substrate, wood, and tree roots creates channels with step-pool morphology. Desktop map reconnaissance was initially performed to locate potential channels that were readily accessible. Field reconnaissance occurred in late-February and March (2018) under normal precipitation 
conditions but when we expected consistent flows with negligible evapotranspiration. Sites were located by starting at the top of the hill and hiking downslope to find the channel (and flowing water) and to locate the initiation point of surface water flow (we initially deemed this as the ephemeral/intermittent point).

The hills are underlain by cyclical sedimentary strata of shales, siltstones, sandstones, and thin limestones of the Dunkard group (Pennsylvanian and early Permian age) (online resource 1). Perched, nonkarst aquifers are common in uplands in this region and are found where relatively impermeable beds of clay or unfractured shale impede the downward movement of groundwater but are isolated from deeper groundwater sources (Shultz 1988). Aquifers are small, recharged only by precipitation, and usually follow the dissected catchments (Cook 2008), discharging as low-flow rheocrene springs and seeps $(<4 \mathrm{~L} / \mathrm{min}$; Shultz 1988). However, spring locations in this region vary and are often dependent on past land movements (e.g., slides, rotational slumps) where then water typically emerges at the toe of the slide. Sharpe (1938) observed that many hills in eastern Ohio, West Virginia, and western Pennsylvania are scarred by thousands of old earthflows and almost the entire surface of certain slopes shows the typical scarps and hummocks of former movements. Photographs of example reaches are provided in online resource 2.

This region experienced near-record setting rainfall in several months during our study period, especially during Tropical Storm Gordon in September 2018 (online resource 3). We compared monthly precipitation totals from NASA's Daymet grid estimates $(1 \times 1$ $\mathrm{km}$ grids) at each site (Thornton et al. 2018) to NOAA's 30-yr precipitation normals (NOAA 2020; https://www.ncdc.noaa.gov/cdo-web/datatools/normals). While monthly site differences were not observed, above average monthly precipitation across the study area occurred in 15 of the 19 months that we measured flow duration (12 months were greater than the NOAA 30-yr 75th percentile, and 2 months were much drier and approached the NOAA 30-yr 25th percentile). In the prior year to study initiation (2017), total precipitation was also above the 75 th percentile in several months, but lower than the 25 th percentile in a few months also (online resource 3 ).

\section{Data collection}

Two reaches were established at each site (dry and flowing). At the flow initiation point (observed in wet season), a 30-m "flowing" reach (either $I$ or $P$ ) was established from this point downstream. A 30-m dry reach (E) was established starting 1-3 m upstream of the flow initiation point. In some instances, $E$ reaches were much shorter when a defined channel ended. The main purpose of the $E$ reach was to compare two rapid flow duration assessment protocols (see below) and to help confirm the location of flow initiation points. We deployed electrical resistance (ER) state loggers at the lowest end of the $E$ reach (Fritz et al 2006), and stream temperature intermittency conductivity (STIC) flow data loggers (Chapin 2014) at the top of the flowing reach to record flow duration and frequency from April 2018 to November 2019. These instruments were set in thalweg areas attached to rebar driven into the streambed. Most ER sensors were eventually replaced with STICs at $E$ sites. We also deployed a game camera to take hourly photographs at one flowing site per study area (Table 1) where the camera was pointed at the STIC logger and used to confirm 
flow or to reconcile any discrepancies in the STIC logger data readouts. Sites were visited 6 times (April 2018, July 2018, October 2018, February 2019, June 2019, and November 2019) for flow logger downloads and maintenance, camera downloads, and to record visual observations of streamflow (visits were made after $48 \mathrm{~h}$ or more of any precipitation).

On three of these occasions (April, October, February), we scored flow duration classes at all sites using existing rapid field assessment protocols: the North Carolina Stream Identification method (NCSI, NCDWQ 2010) and the Ohio Headwater Habitat Evaluation Index (HHEI, OEPA 2018). The NCSI was developed to distinguish $E, I$, and $P$ flow classes and relies on 26 metrics spanning geomorphological, hydrological, and biological observations (presence of aquatic organisms). The HHEI scores the site on substrate characteristics, maximum depth, and bankfull width (BFW) and was developed to distinguish cool-cold water $P$, warmwater $P$ and $I$, and $E$ reaches. We measured channel slope and canopy cover at each site using a hand-held clinometer and spherical densiometer, respectively. Other measurements (flowing reaches only) of Wolman pebble counts (100pebble, 1st visit), and in situ temperature, $\mathrm{pH}, \%$ DO saturation, and specific conductance (3 visits) were recorded.

Macroinvertebrates were collected only from flowing reaches; however, at $E$ sites, we searched for macroinvertebrates under stones and within leaf packs (per the NCSI method). Along the flowing reaches, we sampled macroinvertebrates in April and October (2018), and February, June, and November (2019). Two of the fourteen sites (CEC2 and DYW2) were dry in October 2018 and could not be sampled, and only 6 sites were sampled in November 2019 , as all other sites were dry. A standardized rapid method for step-pool channels was used where we selected 16 stones (8 erosional and 8 depositional cobble-sized stones). These stones were gently scrubbed into a bucket of water with a brush. Three conditioned leaf packs (handfuls) were also rinsed into the bucket. All material was composited and poured through a 500- $\mu \mathrm{m}$ mesh sieve, transferred to 2-L jars, and preserved in $95 \%$ ethanol. In the laboratory, all aquatic organisms were sorted from the detritus and identified to genus or species level, where practical (some species identifications were confirmed with incidental adult or pupal specimens). Flatworms and aquatic annelids were identified to class and family level, respectively.

\section{Catchment GIS characterization}

Site catchments were delineated from the flow initiation point where we derived catchment area and perimeter, elevation, distance from site to highest elevation, relief and relief ratio, mean valley slope, channel distance from site to the origins of blueline streams mapped in the National Hydrography Dataset (NHD, 1:24,000 scale), valley width, soil and bedrock geology, and land cover using ArcMap v10.7 and ArcHydro v2.0 (ESRI, Redlands, CA). Stream definition via flow direction and accumulation grids were developed using 1-m digital elevation models (cell thresholds were selected intuitively based on field observations). Catchments were then delineated from each site's origin and checked with ground observations and leaf-off aerial photography. Catchment land cover metrics were calculated from the 2016 National Landcover dataset (https://www.mrlc.gov/data/nlcd-2016land-cover-conus).

Aquat Ecol. Author manuscript; available in PMC 2021 October 27. 


\section{Data summarization}

We condensed 15-min interval flow data by time periods (total record, yearly, and seasonally). These included proportion of total record flow duration (from April 2018 to November 2019), maximum continuous flow duration, maximum continuous dry duration, and frequency of drying. When STIC logger readouts were less conclusive (i.e., conductivity between 50 and 400 (Jensen et al. 2019), missing data, or altered flowpath), presence of flow was determined using coinciding game camera images, temperature fluctuations, and best professional judgment and then all data were converted to binary observations (flowing or not flowing). These data were used to categorize a site's flow regime and then used as independent variables along with physical habitat measures (e.g., channel characteristics including the NCSI and HHEI scores) to explain macroinvertebrate response (see below). We also evaluated antecedent flow proportions at $30 \mathrm{~d}$ and $60 \mathrm{~d}$ prior to biological sampling. To reduce the number of abiotic variables for testing, we ran Spearman's rank correlation on all variables and inspected those with $r>0.75$. We selected a variable from a colinear pair if it was more strongly correlated with flow duration.

We based our perennial classification as sites with $\geq 85 \%$ flow duration spanning total, 2018, and 2019 time periods. This value split the difference between Hedman and Osterkamp $(1982 ;>80 \%)$ and Hewlett (1982; > 90\%) definitions. Hedman and Osterkamp (1982) also defined intermittent streams as flowing $10-80 \%$ of the year. We used nonparametric Mann-Whitney $U$ tests (Systat Software v13, San Jose, CA) to compare physical habitat and several catchment variables between flow classes. Site temperature data (from the STIC loggers) were summarized for descriptive purposes (i.e., median and quartiles of daily averages, monthly maximum and minimum values). We first condensed the 15-min interval recordings as daily average temperatures, then aggregated by month and flow class, and only used data points where there was a continuous 24-h record of flowing (or dry) conditions.

We calculated several genus- and family-level taxonomic richness and composition metrics, Shannon-Wiener diversity index $\left(\mathrm{H}^{\prime}\right)$, a family-level multimetric index (the West Virginia Stream Condition Index (WVSCI; Gerritsen et al. 2000), and several genus-level trait-based metrics for each sample. These response variables were then compared with physical and flow duration variables. Although macroinvertebrates were sampled via different techniques than what was used to develop the WVSCI, we aimed to comply with WVSCI count requirements ( $200 \pm 20 \%$ individuals) and computer subsampled our full-pick samples to 200 individuals for WVSCI calculation. Macroinvertebrate traits (online resource 4) were assigned to all genera from an EPA database (K. Fritz, EPA unpublished) that was compiled from literature sources (e.g., Vieria et al. 2006; Poff et al. 2006). We excluded some trait metrics from the analysis after screening for range of values (e.g., scrapers, swimmers, warmwater specialists were poorly represented across all samples).

An indicator species analysis (ISA; Cáceres and Legendre 2009) was also performed using genus-level and family-level macroinvertebrates (multipatt function; R Development Core Team 2019). The 54 monthly macroinvertebrate samples were assigned to either $P(n=24)$ or $I(n=30)$ classes (excluding the November 2019 samples). We used monthly samples here to seek reliable indicator taxa for potential use in any season. Briefly, ISA used the product two components: component A (specificity) indicates a taxon's target group 
probability (mean abundance of a taxon at sites within a flow class compared to all study sites), and component B (fidelity) is the relative frequency (frequency of occurrence of a taxon within a flow class relative to all sites). The product of these two values produced an indicator value (IV) and significance was based on 999 Monte Carlo permutations. Raw richness and proportion (of total taxa richness) of the $P$-indicator taxa $(p<0.05)$ were then calculated as additional response variables. The latter proportion-based metric was specifically evaluated for potential use in future assessments if invertebrate sampling methods deviate from ours.

\section{Statistical analyses}

We examined macroinvertebrate response between flow class and along environmental gradients. Between flow classes, mean metric differences were compared with MannWhitney $U$ tests (the six November 2019 samples were excluded because no $I$ sites could be sampled on this date). For significant metrics, we further explored their relationship with flow duration and environmental variables. Initially, we ran Spearman's rank correlation on all macroinvertebrate metrics and abiotic variables. But despite the relatively small spatial extent of our study area, we acknowledged that some degree of spatial autocorrelation was expected based on the clustering of site locations. We first evaluated spatial dependency of individual macroinvertebrate metric response variables and abiotic predictor variables with Moran's $I$. We assigned spatial weights using $k$-nearest neighbor distance $(k=2)$ and then calculated Moran's $I$ coefficients and pseudo- $p$-values from 999 random permutations (GeoDa, v1.17; Anselin et al. 2006). Where single-variable spatial autocorrelations were detected $(p<0.05)$, we checked for data normality (Shapiro-Wilk's test) and then calculated Moran's $I$ on the regression residuals from non-spatial ordinary least squares (OLS) regressions between macroinvertebrate metrics and flow duration. We also estimated potential thresholds or breakpoints in indicator response with flow duration. Here, mean ISA metric values were fitted with both locally weighted scatter-plot smoothing (LOWESS) curves and piecewise linear regression. LOWESS curves provided an initial visual estimate and then piecewise regression models were fitted iteratively to seek the lowest sum of squares and the highest overall $R^{2}$.

To explore patterns of macroinvertebrate assemblage structure among flow classes and seasons (April, Oct, Feb, and June samples), ordination of macroinvertebrate assemblages was performed with non-metric multidimensional scaling (NMDS; PC-ORD, v7) on $\log (\mathrm{x}+$ 1)-transformed abundances with the Bray-Curtis distance measure. Prior to running NMDS, rare taxa (i.e., occurring in $<5 \%$ of all samples) were omitted from the ordination to detect patterns that may be obscured by variability (noise) from rare taxa (McCune and Grace 2002). We visually explored assemblage overlap and clustering based on combinations of flow class, season, and monthly groupings. Environmental and trait vectors were fitted to axes to interpret their influences on assemblage dispersion in ordination space. To further interpret the ordination, we tested within-group and between-group community similarity with multi-response permutation procedure (MRPP; PC-ORD v.7) based on the rank-transformed Bray-Curtis distance matrix. 


\section{Results}

\section{Flow duration and temperature}

Flow instruments in upstream $E$ reaches malfunctioned frequently, and a complete record was not obtained at most sites. Observations of the limited ER and STIC sensor data in these reaches indicated that they only exhibited flow during punctuated rain events with long dry periods in between them (even during the wet season). Alternatively, we made 6 wet and dry season visits and confirmed them dry on all occasions, and thus we were confident that they represented $E$ reaches.

We classified 8 intermittent $(I)$ and 6 perennial $(P)$ sites with STIC logger data. Although total flow duration was strongly correlated with maximum continuous dry, maximum continuous flow duration, and frequency of drying measures $(|x|=0.75-0.87)$, we report all measures in Table 1 and online resource 5, but only used total flow duration as the key predictor variable hereafter. Total flow duration was spatially autocorrelated (Moran's $I=$ $0.65, p<0.01)$ and required further evaluation in its association with macroinvertebrate metrics (see below). Over the total 19-month study period, flow duration at $I$ sites ranged from 45 to $82 \%$, while $P$ sites ranged from 85 to $100 \%$ (Table 2). During the wet season (Nov 1-May 15), all but one of the 14 sites flowed $>95 \%$ of the time (online resource 5). During the 2018 and 2019 dry season (July1 through October 31), I sites showed high variation in proportions of flowing and non-flowing conditions, but $P$ sites flowed more consistently (Fig. 2). Flow duration at $I$ sites during the dry seasons in 2018 and 2019 averaged $41 \%$ and $39 \%$, respectively. In contrast, $P$ sites averaged $92 \%$ and $91 \%$ during dry seasons in 2018 and 2019, respectively (online resource 5).

Surface flow cessation at some $I$ sites corresponded with forest leaf-out (May-June), but at other $I$ sites this onset varied between 2018 and 2019 with cessation starting between July-September (Fig. 2). It should be noted that discharge was not measured, but on most site visits these streams often exhibited only trickle flow and with maximum pool depths ranging from 2 to $12 \mathrm{~cm}$ across all sites and visits (trickle flow here refers to a hydraulic biotope where very low-volume flow trickles through cobbles, gravel, and organic debris with perceptible flow). Game cameras confirmed these trickle flows throughout most of the study duration. We also examined hourly images during and after large precipitation events. For example, at $\mathrm{OHC} 2(P$ site $)$ we observed that after a short-term bankfull discharge event of $1 \mathrm{~h}$ on August 10, 2018 ( $15 \mathrm{~mm}$ storm; Daymet estimate), the stream resumed pre-storm trickle flow after $5 \mathrm{~h}$. However, after a 22-h bankfull pulse on Sept 9-10, 2018 (Tropical Storm Gordon, $\sim 140 \mathrm{~mm}$ rain over $72 \mathrm{~h}$ ), this stream did not resume pre-storm trickle flow for 3 d. At LEW1 ( $I$ site), after a 5-h bankfull event on Aug 2, 2018 ( $40 \mathrm{~mm}$ rain), the channel was dry again $2 \mathrm{~d}$ later. After a 33-h bankfull event spanning the Sept 9-10, 2018, storm, the stream eventually re-dried after $4 \mathrm{~d}$.

Differences in stream temperature were evident between $I$ and $P$ sites (online resource 6). $P$ sites were warmer than $I$ sites in winter months (even when both were flowing), and $P$ sites were cooler in summer months. When sites went dry, channel temperatures displayed much warmer (summer) or colder (winter) daily averages and higher daily extremes indicative of air temperature. One Isite (JUG1) exhibited very high temperature spikes in March-April 
while flowing $\left(25-35^{\circ} \mathrm{C}\right.$; see plot in online resource 6). This was because the catchment faced southward, and the STIC logger was below a bedrock step that received several hours of direct solar radiation before canopy leaf-out. Summer season stream temperatures suggest that our study sites were coldwater streams (WVDEP 2021) as all $P$ sites were predominantly $<19^{\circ} \mathrm{C}$ in June-Aug, while roughly half of the observations at $I$ sites fell below $19^{\circ} \mathrm{C}$ during these summer months.

\section{Physical and GIS variables}

The $P$ sites had significantly larger catchment basins $(p=0.02)$ (Table 2). $P$ sites ranged from 0.62 to 1.52 ha (mean $=0.94$ ha), and $I$ sites ranged from 0.21 to 1.25 ha (mean $=$ 0.49 ha). All channel reaches were relatively steep-sloped and did not differ between flow class where $P$ sites ranged from 19 to $33 \%$ (mean $=27 \%$ ) and $I$ sites ranged from 14 to $48 \%$ (mean $=31 \%$ ). No statistical differences between $I$ and $P$ sites were observed for other physical or GIS characteristics (elevation, mean valley slope, relief ratio, bankfull width). Site elevations to the highest elevation within catchments ranged from 31 to $91 \mathrm{~m}$ at $P$ sites $($ median $=51 \mathrm{~m})$ and $15-66 \mathrm{~m}$ at $I$ sites $($ median $=35 \mathrm{~m})$. Down-gradient distances between site locations to origins of NHD $24 \mathrm{k}$ streamlines ranged from 246 to $521 \mathrm{~m}$ at $P$ sites (mean $=349 \mathrm{~m}$ ) and from 223 to $640 \mathrm{~m}$ at $I$ sites $($ mean $=416 \mathrm{~m}$ ), indicating that the NHD layer potentially omits considerable stream lengths across this ecoregion. Substrate sizes (\% fines, $\mathrm{D}_{50}, \%>256 \mathrm{~mm}$ ) varied among sites and were not significantly different between flow classes. Specific conductance was significantly greater at $P$ sites; however, this result was largely driven by one site (CEC1) that consistently had elevated values. Dissolved oxygen saturation and $\mathrm{pH}$ did not differ significantly between $P$ and $I$ sites.

Compared with STIC loggers, the rapid field assessments (NCSI and HHEI) gave mixed results with varying misclassification (total overall error) rates (Fig. 3). Within flow classes, scores were relatively similar between wet and dry seasonal visits. Misclassification rates across all sample events for NCSI were low for $E$ and $I$ sites (13\% and 8\%, respectively), but this method performed poorly in distinguishing $P$ sites from I sites (79\% error). The HHEI was also variable where $E, I$, and $P$ sites were misclassified $28 \%, 25 \%$, and $46 \%$ of the time, respectively. Between $I$ and $P$ sites, we found that 2 of the 6 metric groups (combined biology score of NCSI and the substrate score of HHEI) were significantly greater at $P$ sites (Mann-Whitney $U$ test, $p<0.03$ ).

\section{Macroinvertebrates}

No aquatic macroinvertebrates were found at $E$ sites during any of the visits of the dry channels. At flowing sites, a total of 13,269 aquatic individuals were collected representing 135 distinct taxa from 121 genera and 47 families over 60 sampling events. Over half of the genera observed belonged to EPT ( 30 genera) and Chironomidae (36 genera) (online resource 7). Total individuals per sample were not significantly different between flow classes $(p=0.09) . P$ sites ranged from 86 to $648($ mean $=245.5, \mathrm{SD}=128.8)$, and $I$ sites ranged from 38 to $719($ mean $=196.8, \mathrm{SD}=130.4)$.

ISA produced 22 genera and 15 families indicative of $P$ streams (Table 3 ), and only one genus was a significant $I$ stream indicator (the ceratopogonid $C$ ulicoides). Components A

Aquat Ecol. Author manuscript; available in PMC 2021 October 27. 
and B of the ISA revealed that most taxa had high specificity to the $P$ flow class (component A), but several were less common across all $P$ samples (component B). For instance, the beetle Ectopria and the mayfly family Ephemerellidae specified a perennial stream $100 \%$ of the time but were only found in $30 \%$ of the $P$ samples. In contrast, the hydropsychid caddisfly Diplectrona also indicated $P$ streams $100 \%$ of the time but was more common (i.e., $70 \%$ probability of capture). Among $I$ sites, at least one $P$-indicator taxon occurred in $86 \%$ of samples collected. The relative frequencies for all taxa listed by flow class and wet or dry seasons are presented in online resource 7 .

On average (means across seasons), several metrics (richness, indicator-based, trait-based, and WVSCI) could significantly discriminate between $I$ and $P$ flow classes (Mann-Whitney $U$ tests, Table 4). Genus-versus family-level metric comparisons were highly correlated ( $\mathrm{r}>$ 0.90 ), but we reported both to compare their relative strengths in distinguishing flow class. In all comparisons, $P$ sites had greater richness and diversity and greater $P$-indicator richness and proportion of $P$-indicator taxa. In most instances, family-level metrics performed similarly or better than genus-based metrics. Trait-based relative abundance metrics were not as powerful in distinguishing flow class compared to richness, diversity, or ISA metrics. The relative abundance of filterers, drifters, rheophiles, and slow developers was greater at $P$ sites, while air breathers, burrowers, and predators were more prevalent at $I$ sites. Monthly comparisons of select metrics showed some seasonal variability, but flow class was largely deterministic (Fig. 4). For the WVSCI, all $P$ sites and roughly $50 \%$ of the $I$ samples would pass the WVSCI ALU attainment threshold of 72.

Two trait-based richness metrics (raw semi + univoltine richness and low dispersal richness) were also significantly greater at $P$ sites $(p<0.01$, Table 4$)$. Overall, the study reaches had a greater proportion of low dispersing taxa richness (range $=53-0 \%$ ) than high dispersing taxa (18-40\%), but no differences were detected between $P$ and $I$ sites $(p>0.1)$. Desiccationresistant taxa made up a substantial proportion at all sites and did not differ between $P$ and $I$ sites $(p=0.20)$ where $P$ sites ranged from 22 to $55 \%$ (mean $=38 \%)$ and $I$ sites ranged from 28 to $60 \%$ (mean $=40 \%)$. Coldwater stenotherms also made up a relatively high proportion of all taxa collected across all sites (range $=31-8 \%$ ) but did not differ significantly between flow classes $(p=0.52)$.

\section{Macroinvertebrate metric relationships with flow duration and physical variables}

Several biological metrics responded strongly along the flow duration gradient and moderately with some physical variables (Spearman correlations, online resource 8). However, many of the macroinvertebrate metrics, total flow duration, and catchment area were spatially autocorrelated (Table 5; Moran's $I>0.4, p<0.05$ ). Other abiotic variables (substrate sizes, BFW, slope, NCSI, HHEI, specific conductance) were not. Where significant, this necessitated testing for spatial dependency on the regression residuals between macroinvertebrate metrics and flow duration. We did not find spatial autocorrelation affected the relationship between metrics and flow duration (Moran's $I p>0.1$ for all regressions).

Metrics were normally distributed (Shapiro-Wilk's, $p>0.05$ ). OLS regressions between mean metric values and flow duration (Table 5) showed that the proportion of $P$-indicator 
(family) had the strongest response to increasing flow duration $\left(R^{2}=0.76\right)$, followed by EPT richness (genus) and $P$-indicator (family) richness $\left(R^{2}=0.67\right.$ and 0.66 , respectively). Differences in explained variance of genus versus family-level metrics were negligible. The multimetric WVSCI was also strongly related to flow duration $\left(R^{2}=0.60\right)$, but Shannon diversity relationships were more moderate in their response $\left(R^{2}=0.40\right)$. The trait-based relative abundance metrics that were significantly related with flow duration included $\%$ filterers $\left(R^{2}=0.60\right), \%$ predators $\left(R^{2}=048\right), \%$ drifters $\left(R^{2}=0.47\right), \%$ rheophiles $\left(R^{2}=\right.$ 0.32 ), and \% burrowers $\left(R^{2}=0.30\right)$. At the time of macroinvertebrate sampling, proportions of 30-d and 60-d antecedent flow did not influence EPT generic richness (Spearman's $r=$ 0.19 and 0.28 , respectively) or $P$-indicator family richness (Spearman's $r=0.14$ and 0.21 , respectively), and thus, longer period flow duration measures explained more variation.

LOWESS curve fitting and subsequent piecewise regression revealed a distinctive flow duration threshold for $P$-indicator families (richness and proportional richness) at $77 \%$ (Fig. 5). Both indicator metrics showed a steep increase in value at this threshold (corresponding with $2.9 P$-indicator families and 0.30 proportion). Piecewise regression marginally improved the fit over the OLS regression in both metrics $\left(R^{2}=0.73\right.$ for $P$-indicator richness and 0.79 for proportion $P$-indicator richness).

Physical habitat and GIS variables explained less in metric variation overall (online resource $8)$, but catchment area was best correlated with mean genus-level taxa richness $(r=0.69)$ and family-level $P$-indicator richness $(r=0.71)$. Among all environmental variables, genuslevel EPT richness was most strongly correlated with increasing specific conductance $(r$ $=0.71)$. The relative abundance of desiccation-resistant taxa was moderately correlated with frequency of drying $(r=0.65)$ but less with the other flow gradient measures $(|r|=$ 0.38 ). Substrate size had some effect on trait metrics where increasing $D_{50}$ was moderately correlated with the proportion of rheophilic taxa $(r=0.67)$ and larger substrate $(\%>256$ $\mathrm{mm})$ negatively correlated with $\%$ shredders $(r=-0.67)$. The relative abundance of EPT was inversely correlated with channel slope only $(r=-0.68)$.

\section{Macroinvertebrate ordination}

The NMDS produced a 3-dimensional solution with low stress ( 0.12 after 48 iterations). After orthogonal rotation, axis 1 accounted for $43 \%$ of the variance compared to $30 \%$ for axis 2 axis (based on the correlation of the original and final distance matrices). Axis 3 accounted for only $13 \%$ and was not plotted or analyzed further. Grouped by flow class ( $I$ vs $P$ ) and wet (April and February) and dry seasons (October and June), a relatively strong pattern was visualized with good separations (Fig. 6). Vector correlations with each axis indicated a moderately strong seasonal gradient along axis 1 (Julian day; $r=-0.61$ ), but axis 2 was driven mainly by flow permanence. Total flow duration was the strongest driver of assemblages along axis $2(r=-0.70)$ followed by frequency of drying $(r=$ $0.60)$. Catchment area $(r=-0.54)$ and channel slope $(r=0.46)$ also explained variation in assemblage dispersion. Physical and GIS variables (substrate size, BFW, NCSI, HHEI, basin perimeter, relief ratio, elevation, mean valley slope) explained less variation in assemblages along either axis $(|x|<0.33)$. Overall, the MRPP indicated higher differences in average between-group dispersion with lesser within-group differences ( $\mathrm{T}=-19.7, A=0.45, p<$

Aquat Ecol. Author manuscript; available in PMC 2021 October 27. 
$0.0001)$. Despite less visual overlap of $P$-dry and $I$-dry sites in ordination space, among all pairwise comparisons they were most similar $(\mathrm{T}=-3.7, A=0.08)$. In contrast, $I$-wet vs $I$-dry showed the most dissimilarity ( $T=-15.7, A=0.38$ ). Within-groups, $I$-wet, and $I$-dry had the lowest and highest average distance (Bray-Curtis; 0.18 and 0.42 , respectively).

Several genera were strongly correlated with NMDS axes 1 and 2 ( $|x|>0.6$; Fig. 6). The mayflies Ephemerella, Epeorus, and Paraleptophlebia, the caddisfly Diplectrona, the stoneflies $S$ weltsa and Amphinemura, and the midge Tvetenia responded particularly to the flow duration gradient in ordination space (axis 2). Seasonal taxonomic patterns (axis 1) were also evident as some taxa exhibited correspondence with wet or dry seasons. The dipterans Dixa, Dicranota, and Corynoneura were collected more commonly in the dry season, and Stegopterna black-flies were found exclusively in the wet season. Two nemourid stoneflies showed opposite seasonality where Ostrocerca was found exclusively in the wet months, while Soyedina was most prevalent in the dry months. The hydrophilid beetle Cymbiodyta also was more prevalent in the dry months. None of these axis 1 taxa were strongly correlated with flow duration in ordination space.

Several trait-based metrics were also related to assemblage dispersion (Fig. 6). For instance, on axis $1, \%$ shredders $(r=0.67)$ and $\%$ slow developers $(r=-0.64)$ showed strongest seasonal correspondence, whereas on axis $2, \%$ burrowers $(r=0.68)$ and $\%$ semi + univoltine $(r=0.50)$ aligned more closely with the flow duration signal. Trait-based metrics that displayed diagonal vectors suggested that season and flow duration both drove their abundances. For example, \% limnophiles (axis $1 r=-0.50$, axis $2 r=0.55$ ) and proportion of rheophiles (axis $1 r=-0.50$, axis $2 r=0.44$ ) displayed opposite trajectories.

\section{Discussion}

Given the essential contribution of headwater streams to biodiversity and downstream water quality, conservation of these source headwater habitats benefits the chemical, physical, and biological integrity of the nation's waters (Schofield et al. 2018). There remains a critical need to classify streams based on their flow permanence, and development of rapid biological and physical indicator methodologies can provide data to support classifications (Fritz et al. 2020). Accurate classifications are important for CWA programs where small streams might be subjected to discharged pollutants or physical disturbance. Stream disturbance from hillslope and riparian encroachment is often magnified in these systems, attributable to the shear proximity of the disturbance to the habitat and the small size of the habitat (e.g., Jones et al. 2000; Gomi et al. 2002). Indeed, rheocrene habitats like ours are at increasing risk from water depletion and degradation from common land uses across the Western Allegheny Plateau (e.g., hilltop development, mining, pipelines, agriculture).

Our study sites represented the headwater position of where flowing channels begin, and where diverse coldwater aquatic communities can occur. Though locally variable, we found that flow origins of $I$ and $P$ reaches occurred within $\sim 35$ to $\sim 50 \mathrm{~m}$ in elevation from the drainage divide and with catchment areas typically less than 1 ha. Incidentally, these $I$ and $P$ stream channels do not appear on available maps and are too small to be visible from aerial imagery but could potentially be considered jurisdictional streams based on 
their documented flow regime (and the macroinvertebrates that inhabit them). Spatially, there was a tendency for longer flow duration in the eastern portion of our study area. While baseflow discharge is seasonally variable, low-volume trickle flow predominated throughout the seasons. This was especially noted in the growing season where $>50 \%$ of precipitation is lost to evapotranspiration (Shultz 1988). Although precipitation was above average during our study, the fact that our catchments are very small and that groundwater recharge follows their drainage divides (Cook 2008; Bates et al. 2015), much of the surplus precipitation was exfiltrated as short-term runoff (as evidenced from game camera images following rain events) as channels resumed trickle flow or dryness within hours or a few days after high precipitation events. However, we acknowledge that during drought years, evapotranspiration in the growing season could affect flow duration at these forested sites.

\section{Physical and chemical indicators}

The step-pool rheocrene habitat we observed is distinctive where portions of the reach resembled upstream heterogeneous zones (UHZs), with high ratio of structural component size (e.g., substrate particle diameter and woody debris; see online resource 2) to stream width as described by Gooderham (2007). Low-velocity baseflows in UHZs have low competence to move and sort sediments like in larger streams (Gooderham 2007) but still provide ample habitat to lotic specialists. Other portions of our reaches exhibited stronger channel development with distinct thalwegs where episodic floods have influenced channel morphology over time.

The habitats of $P$ and $I$ streams were similar and thus few physical indicators could distinguish them. While catchment area was significantly different between flow classes, there was still considerable overlap and high variability, preventing reliable use of this measure with GIS from the desktop in the Permian Hills subecoregion. However, our results suggest that for $I$ catchments a range of $0.25-1$ ha could be used as an initial cut for determining potential of a flow regime suggestive of jurisdictional streams in this subecoregion. Our $I$ and $P$ study catchments were considerably smaller than those reported by Paybins (2003) in the dissected central Appalachian Plateau in southern West Virginia. She reported that $I$ streams originated at $\sim 6$ ha (median) and 16 ha for $P$ streams. This difference underscores the need to determine characteristics of flow duration in an ecoregional context.

The 2 rapid assessment methods (NCSI and HHEI) we employed did a better job at distinguishing the $E$ class, but they overlapped considerably between $I$ and $P$ classes. Fritz et al. (2008) also detected differences in NCSI and HHEI scores of $E$ from $I$ and $P$, but not between $I$ and $P$. Similarly, Fritz et al. (2013) reported that in South Carolina, the NCSI did not differentiate $I$ and $P$ classes effectively either. Further, caution is advised for using HHEI in rheocrene springs $<25$ ha (OEPA 2018) because they might not exhibit channel characteristics like streams that the OEPA calibrated the index from. OEPA recommends that biological surveys are performed in these rheocrene systems. However, if the goal of a flow duration assessment is to simply identify $E$ from other types (combined $I$ and $P$ stream classes), the NCSI appears to be reliable in our study streams. We believe that the reasons these rapid techniques could not distinguish $I$ from $P$ reaches nor explain 
macroinvertebrate assemblages are because our $I$ and $P$ reaches were physically similar and that perennial indicators are often less discernable in spring reaches (NCDEM 2009). Since 11 of 26 total NCSI are geomorphology based, the physical similarity among study reaches produced a narrow gradient of rapid assessment scores for correlation-type analysis. However, the summed NCSI biology subset metric ( 9 combined metrics) and the HHEI substrate metric distinguished $I$ and $P$ reaches, indicating that aquatic organisms and substrate were important indicators of flow class.

\section{Macroinvertebrate indicators}

Biologically, our low-volume step-pool rheocrenes harbored diverse suites of obligate aquatic macroinvertebrates, many taxa of which are also frequently encountered in larger wadeable streams. Our $P$ sites clearly had more total and EPT taxa across most sample months. While this observation conforms with Soria et al. (2017), several researchers (e.g., Feminella 1996; Bonada et al. 2007; Santos and Stevenson 2011; Grubbs 2011; Kelso and Entrekin 2018) have found comparable species richness between $I$ and $P$ streams (but their streams were considerably larger than the ones we studied). Although ephemeral streams in this region do not provide flowing habitat of sufficient duration for maintenance of macroinvertebrate populations, intermittent streams certainly do.

While most of the taxa that we encountered commonly occur in larger wadeable reaches (author observations, agency databases, Eaton and Vander Vorste 2012), we collected several taxa that are known headwater or rheocrene specialists and do not frequently occur in agency wadeable stream monitoring databases. For example, niche specialists included the hydropsychid caddisflies Homoplectra doringa and Diplectrona metaqui and the limnephilid caddisfly Pseudostenophylax. The trickle-midge Thaumalea, the nemourid stoneflies Soyedina and Ostrocerca, and the crane flies Pedicia, Ormosia, and Molophilus are also headwater specialists that we encountered. The chironomid midge fauna was distinctive too. Midges are generally short-lived macroinvertebrates and often eurytopic, but we found several coldwater, headwater specialists (e.g., Boreochlus, Parachaetocladius, Heleniella, Pagastia, Stempellinella, Stilocladius; Bolton 2012). On average, $\sim 40 \%$ of all taxa collected across flow class and seasonal samples were coldwater stenotherms which aligned with our temperature observations (no observed taxa were designated as warmwater specialists). We believe that these example niche specialists are vulnerable to disturbance in small rheocrenes in the region.

Between flow classes, the ISA produced subsets of genera and families that could indicate $P$ sites; however, many taxa were ubiquitous across $P$ and $I$ sites. Many of the significant indicator genera are ones frequently found in larger headwater streams but populate small rheocrenes too. The similar discriminatory power and responsiveness of family-level $P$ indicator metrics (versus genus-level) suggests that these metrics could be used as reliable rapid assessment indicator with faster and less-costly identification time, and with potential for rapid field identifications (compared to genus-level). Further, our study sites belong to a subset of headwater streams that are not routinely monitored or assessed for ALU attainment by government agencies under the CWA. Our data suggest that existing assessment tools, such as WVSCI, could potentially be used for CWA assessments here. The fact that many 
of our small rheocrenes produced attaining WVSCI scores (despite being calibrated for wadeable streams) further implies that they indeed harbor aquatic assemblages exceeding metric expectations of ALUs that the CWA intended to protect. However, we emphasize that our data are not directly transferable to WV assessment methodology (different sampling techniques and smaller streams).

Several trait-based metrics were ecologically intuitive and showed moderate capabilities to distinguish $P$ and $I$ classes. In Mediterranean streams of northeast Spain, Bonada et al. (2007) found few macroinvertebrate traits could explicitly indicate perennial streams, but more could distinguish intermittent and ephemeral streams. In small rheocrene springs, our data suggest that the relative abundance of lotic-related traits (i.e., drifters, filterers and rheophiles), lentic-related traits (i.e., burrowers, air breathers), and taxa with slow development life histories (chiefly caddisflies, crane flies, and several stoneflies) could be evaluated when determining flow status with macroinvertebrates. Further, we believe that in our $P$ and $I$ streams, the frequent presence and high abundance of univoltine (and a few longer-lived semivoltine) taxa with affinities to flowing water could biologically support flow permanence determinations for regulatory purposes. Numerous univoltine taxa were frequent residents of our $I$ and $P$ streams and would not be found in $E$ streams. These univoltine taxa displayed aspects of resilience and resistance traits. For instance, low-distance dispersing taxa were more diverse than high-distance dispersers overall, indicating that most of the taxa can colonize reaches from nearby habitat patches or adjacent tributaries; however, this could hinder recolonization of disturbed streams that become fragmented or isolated (Robson et al. 2011). Further evidence of community resistance was observed with similarly high proportions of desiccation-resistant taxa found routinely at both $P$ and $I$ sites where resident assemblages have evolved mechanisms to deal with uncertainty in drying harshness (Robson et al. 2011; Stubbington and Datry 2013). We acknowledge that macroinvertebrates can display spatiotemporal trait plasticity across environments (e.g., adjusting to local habitat conditions and food resources). However, we still observed relatively strong response signals in trait composition related to flow duration.

Between flow classes and seasons, we saw indicative trends in some trait-based metrics (online resource 9 and Fig. 6). A secondary ISA of 4 groups ( 2 flow classes and 2 seasons) produced several indicator taxa for each and pairwise tests of traits alluded to the strong influence of both flow class and seasonality. Combining traits with indicator families, signature patterns emerged in our dataset (Fig. 7). These patterns are plausible given both seasonal taxon-specific life history phenologies and the drying constraints on macroinvertebrates (Williams 1996). Taxonomically, 11 out of 15 of our family ISA-produced $P$ indicators (see Table 3 ) corresponded with North Carolina's indicator list (NCDWQ 2010). Two additional taxa occurred mutually among $I$ and $P$ sites (Lepidostomatidae and Rhyacophilidae; Fig. 7) but are considered perennial indicators in North Carolina. Ecological associations from trait-based indicators were also insightful as relative abundances shifted between flow class and seasonal groupings, presumably driven by life history adaptations and tolerances to prevailing flow conditions (e.g., Walters 2011). For instance, at $I$ sites during the dry season, the relative abundance of non-lotic specialists (limnophiles, air breathers, and burrowers) increased. However, at $P$ sites during the dry season, these non-lotic trait abundances were reduced, and slow developers were greater. 
Although \% desiccation-resistant invertebrates were relatively common and similar at all sites (no significant difference when averaged across seasons), they were greatest at $I$ sites during the winter-spring wet season. Intuitively, this suggests pheno-logical cues and adaptations in taxa able to endure impending drying conditions. However, this observation contrasted with Walters (2011) who did not find differences in desiccation-resistant taxa between spring and summer, but her work was done in larger Connecticut streams where flows were experimentally diverted. We also found that predators increased at $I$ sites (and slightly in $P$ ) in the dry season as conceptualized by Williams (1996). Here, predators might represent a "clean-up crew," theoretically taking advantage of the increased crowding of other macroinvertebrate prey in a shrinking aquatic habitat. These patterns should be tested in more streams of varying flow permanence across the region.

\section{Flow duration and seasonality as the drivers}

As predicted, macroinvertebrate diversity responded strongly along a gradient of total flow duration in our study streams. Even trickle flows among cobble and leaf packs in the dry season provided sufficient habitat for high taxonomic richness of obligate aquatic macroinvertebrates (and nearly half of them were coldwater stenotherms). However, sites with the lowest flow duration (and enduring the longest periods of continuous channel dryness) had reduced richness, especially EPT and $P$-indicator taxa, as expected. These smallest $I$ streams probably experience levels of drying harshness that limit colonization and long-term population maintenance of many lotic taxa. Despite minor spatial influence on flow duration across the study area, spatial variation alone was not an underlying factor since regression residuals were not spatially dependent. For instance, when comparing taxa lists between our smallest driest streams in the south (JUG) versus the wettest sites in the north $(\mathrm{OHC}), 89 \%$ of the taxa found among JUG reaches also occurred in OHC reaches (i.e., assemblage-wise, the southern sites with shorter flow duration contained a subset of taxa found in northern streams having longer flow duration). Along a river system in France, Datry (2012) also showed that assemblages from the most intermittent sites were nested subsets of assemblages from the most perennial sites.

As expected, we observed marked seasonal differences in assemblage structure within both flow classes, but many taxa overlapped across sampling months. Most winter-spring or summer-fall occupants (especially EPT taxa) are specifically linked with seasonal cues (e.g., temperature, food resources, and photoperiod) that influence the timing of life history events (Sweeney 1984). Macroinvertebrate life history phenology associated with environmental cues strongly influences assemblage composition (Sweeney 1984; Straka et al. 2012). Despite strong seasonal differences in assemblages (NMDS 1), distances along NMDS 2 were largely driven by greater flow duration and lower frequency of drying and several of the taxa that helped shape observed dispersion were ones identified as $P$-indicators. A few of these indicator taxa were winter-spring occupants (Ephemerella, Epeorus, Amphinemura), while Diplectrona and $S$ weltsa were found in both seasons. During the wet season, $I$ and $P$ assemblages were more variable and showed less resemblance in multivariate space (MRPP and centroid distance); however, during the dry season $P$ and $I$ sites were relatively more similar, a probable result of homogenization by replacing winter-spring specialists with 
increases in more ubiquitous summer-fall Diptera (e.g., ceratopogonids and chironomids) and EPT such as Soyedina, Lepidostoma, and Rhyacophila (online resource 7).

During dry periods, our study reaches afforded ample refugia (e.g., Stubbington et al. 2017) for macroinvertebrate including large stones, isolated shallow pools or saturated sediments, woody debris, inundated crayfish burrows, and shallow subsurface flow pathways (Collins et al. 2007; Dole-Oliver 2011). Although we did not sample macroinvertebrates in dry $I$ reaches, we observed that when they were not flowing, substrates often remained moist and we believe that heavy canopy cover might also maintain high humidity levels for macroinvertebrates to survive for several weeks (e.g., Storey and Quinn 2013; Stubbington et al 2017; Paril et al. 2019). Moreover, removal of large stones or shallow digging in these channels often revealed the presence of interstitial moisture within fine sediments. Thus, while measured surface flow can explain macroinvertebrate persistence, it does not fully characterize macroinvertebrate habitat availability and refugia.

Many of the macroinvertebrate taxa encountered have evolved life history traits to survive in these small streams during times of drying. Desiccation tolerance (through aestivation, or egg or larval diapause; Stubbington et al 2017) is common in the nemourid and capniid stoneflies, tipuloid crane flies, several chironomid midge genera, and aquatic worm families that we observed. Egg diapausing taxa (those with desiccation-resistant eggs) resist local extirpation and contribute to viable drought-resistant seedbanks and assist in recovery of the community upon flow resumption (Stubbington and Datry 2013). Dry sediment rehydration experiments (e.g., Storey and Quinn 2013; Stubbington and Datry 2013) have revealed that many taxa become active within days to weeks following inundation.

Cohort splitting implies another evolved trait to persist under uncertain drying conditions whereby some species produce 2 overlapping subpopulations throughout the year (Robson et al. 2011). Incidentally, we observed two separate size classes of univoltine species Diplectrona modesta, Rhyacophila parantra, Peltoperla arcuate, and Wormaldia moesta within individual monthly samples. In contrast, Soyedina vallicularia exhibited a slowdeveloping single cohort and likely sought temporary refuge during periods of flow cessation (unlike most nemourid stoneflies, this genus does not undergo a summer diapause phase; Harper 1973). Hence, we acknowledge that community persistence in small rheocrene habitats can occur through the combination of resistant taxa and community resilience via patch refugia, desiccation tolerance, cohort splitting, invertebrate seedbank viability, and organism dispersal processes (Bogan et al. 2017; Stubbington et al. 2017). Persistence during dry times would also be heavily reliant on instream habitat quality such as substrate heterogeneity and stability, leaf litter, and dense stream canopy cover to maintain substrate humidity, sediment moisture, and cooler temperatures.

\section{Recommendations}

Flow duration shapes macroinvertebrate biodiversity and assemblage structure in small $(<1 \mathrm{ha})$ rheocrene springs in this region. Accordingly, we recommend evaluation of macroinvertebrate assemblages when performing flow permanence determinations and tools should be refined or developed to use macroinvertebrates to assess ALU's under the CWA 
in these systems. Whereas genus- or species-level data would best represent ALUs and have better ability at assessing stream health and diagnosing stressors (e.g., Lenat and Resh 2001), the family-level WVSCI could potentially be used for stream condition monitoring in rheocrene springs across our study region. For flow permanence determinations, more rapid family-level indicators are appropriate for our stream types, but because of temporal variation in taxa and traits, indicators should be considered under a seasonal framework. With more data, we believe that a multimetric index or predictive model incorporating indicator taxa and trait metrics (e.g., Straka et al. 2019) could be developed for determining flow permanence in this region. Rapid physical field assessments for flow duration (NCSI or HHEI) also provide important information. Although they did not adequately differentiate our $I$ and $P$ streams effectively, they did distinguish the dry $E$ streams and can support flow permanence determinations in this ecoregion. When planning for future earth disturbance activities involving headwater streams, land developers should also deploy STIC-type loggers for flow duration determinations. We believe the findings presented here could help guide management of these resources through future land use planning, and CWA monitoring and assessment.

\section{Supplementary Material}

Refer to Web version on PubMed Central for supplementary material.

\section{Acknowledgements}

This study was inspired by our former EPA colleague, Margaret Passmore (retired). We thank our colleagues Kristopher DeNardi (EPA) and Michael Treese (ASCR Federal) for GIS support, Amy Bergdale, Frank Borsuk, David Light, Todd Lutte, and Lou Reynolds (EPA) for field and analytical support and David Campbell and Jennifer Fulton for managerial support. The draft manuscript was reviewed and improved by Ken Fritz, Mike McManus and Stefania Shamet (EPA), Sally Entrekin (Virginia Tech), and 2 anonymous reviewers. Although this research was supported by EPA, the views and opinions expressed in this article are those of the authors and do not necessarily reflect the views or policies of the EPA or the US government. We dedicate this paper to Benjamin Mortimer Stout, III (1957-2018).

\section{Data availability}

Available from the primary author, with reasonable request.

\section{References}

Anselin L, Syabri I, Youngihn K (2006) GeoDa: an introduction to spatial data analysis. Geogr Anal 38(1):5-22

Bates NS, Smith JA, Villarini G (2015) Flood response for the watersheds of the Fernow experimental forest in the central Appalachians. Water Resour Res 51:4431-4453

Bishop K, Buffam I, Erlandsson M, Folster J, Laudon H, Seibert J, Temnerud J (2008) Aqua incognita: the unknown headwaters. Hydrol Proc 22(8):1239

Bogan MT, Chester ET, Datry T, Murphy AL, Robson BJ, Ruhi A, Stubbington R, Whitney JE (2017) Resistance, resilience, and community recovery in intermittent rivers and ephemeral streams. In: Datry T, Bonada N, Boulton A (eds) Intermittent rivers and ephemeral streams: ecology and management. Elsevier, London, pp 349-376

Bolton MJ (2012) Ohio EPA supplemental keys to the larval Chironomidae (Diptera) of Ohio and Ohio Chironomidae checklist. Ohio Environmental Protection Agency, Division of Surface Water, Groveport, $\mathrm{OH}$ 
Bonada N, Rieradevall M, Prat N (2007) Macroinvertebrate community structure and biological traits related to flow permanence in a Mediterranean river network. Hydrobiologia 589(1):91-106

Brown BL, Swan CM (2010) Dendritic network structure constrains metacommunity properties in riverine ecosystems. J Anim Ecol 79(3):571-580 [PubMed: 20180874]

Chapin TP, Todd AS, Zeigler MP (2014) Robust, low-cost data loggers for stream temperature, flow intermittency, and relative conductivity monitoring. Water Resour Res 50(8):6542-6548

Collins BM, Sobczak WV, Colburn EA (2007) Subsurface flowpaths in a forested headwater stream harbor a diverse macroinvertebrate community. Wetlands 27(2):319-325

Cook SR (2008) The hydrogeology of an old growth forest with implications for defining impact zones associated with underground mining. Dissertation, Ohio University

Cáceres MD, Legendre P (2009) Associations between species and groups of sites: indices and statistical inference. Ecology 90(12):3566-3574 [PubMed: 20120823]

Datry T (2012) Benthic and hyporheic invertebrate assemblages along a flow intermittence gradient: effects of duration of dry events. Freshw Biol 57(3):563-574

Dole-Olivier MJ (2011) The hyporheic refuge hypothesis reconsidered: a review of hydrological aspects. Mar Freshw Res 62(11):1281-1302

Eaton L, Vander Vorste R (2012) Final Report: Documenting Significant Nexus to Navigable Waters in the Southeast. NC Division of Water Quality, NC Department of Environment and Natural Resources, Raleigh, NC. Retrieved from: http://www.ncwetlands.org/wp-content/uploads/EatonVander-Vorste-Significant-Nexus-Headwater-Streams-FINAL-REPORT-2012.pdf

Feminella JW (1996) Comparison of benthic macroinvertebrate assemblages in small streams along a gradient of flow permanence. J N Am Benthol Soc 15:651-669. 10.2307/1467814

Finn DS, Bonada N, Múrria C, Hughes JM (2011) Small but mighty: headwaters are vital to stream network biodiversity at two levels of organization. J N Am Benthol Soc 30(4):963-980

Fritz KM, Glime JM, Hribljan J, Greenwood JL (2009) Can bryophytes be used to characterize hydrologic permanence in forested headwater streams? Ecol Ind 9:681-692. 10.1016/ j.ecolind.2008.09.001

Fritz KM, Johnson BR, Walters DM (2008) Physical indicators of hydrologic permanence in forested headwater streams. J N Am Benthol Soc 27:690-704. 10.1899/07-117.1

Fritz KM, Nadeau TL, Kelso JE, Beck WS, Mazor RD, Harrington RA, Topping BJ (2020) Classifying streamflow duration: the scientific basis and an operational framework for method development. Water 12(9):2545. 10.3390/w12092545

Fritz KM, Wenerick WR, Kostich MS (2013) A validation study of a rapid field-based rating system for discriminating among flow permanence classes of headwater streams in South Carolina. Environ Manag 52:1286-1298. 10.1007/s00267-013-0158-x

Fritz KM, Johnson BR, Walters DM (2006) Field operations manual for assessing the hydrologic permanence and ecological condition of headwater streams. EPA/600/R-06/126, US Environmental Protection Agency, Office of Research and Development, Washington DC

Gerritsen J, Burton J, Barbour MT (2000) A stream condition index for West Virginia wadeable streams. Tetra Tech, Inc., Owings Mills, Maryland. http://dep.wv.gov/wwe/watershed/bio_fish/ documents/wvsci.pdf

Gomi T, Sidle RC, Richardson JS (2002) Understanding processes and downstream linkages of headwater systems: headwaters differ from downstream reaches by their close coupling to hillslope processes, more temporal and spatial variation, and their need for different means of protection from land use. Bioscience 52(10):905-916

Gooderham JPR, Barmuta LA, Davies PE (2007) Upstream heterogeneous zones: small stream systems structured by a lack of competence? J N Am Benthol Soc 26:365-374. 10.1899/06-067.1

Griffith MB, Perry SA (1993) The distribution of macroinvertebrates in the hyporheic zone of two small Appalachian headwater streams. Archiv Fuer Hydrobiologie 126(3):373-384

Grubbs SA (2011) Influence of flow permanence on headwater macroinvertebrate communities in a Cumberland Plateau watershed, USA. Aqua Ecol 45:185-195

Harper PP (1973) Life histories of Nemouridae and Leuctridae in southern Ontario (Plecoptera). Hydrobiologia 41(3):309-356 
Hedman ER, Osterkamp WR (1982) Stream flow characteristics related to channel geometry of streams in western United States. US Geological Survey Water-Supply Paper 2193

Hewlett JD (1982) Principles of forest hydrology. University of Georgia Press, Athens, Georgia

Hose GC, Jones P, Lim RP (2005) Hyporheic macroinvertebrates in riffle and pool areas of temporary streams in south eastern Australia. Hydrobiologia 532:81-90

Jensen CK, McGuire KJ, McLaughlin DL, Scott DT (2019) Quantifying spatiotemporal variation in headwater stream length using flow intermittency sensors. Environ Monit Assess 191(4):191-226 [PubMed: 30810872]

Johnson BR, Fritz KM, Blocksom KA, Walters DM (2009) Larval salamanders and channel geomorphology are indicators of hydrologic permanence in forested headwater streams. Ecol Ind 9:150-159. 10.1016/j.ecolind.2008.03.001

Jones JA, Swanson FJ, Wemple BC, Snyder KU (2000) Effects of roads on hydrology, geomorphology, and disturbance patches in stream networks. Conserv Biol 14(1):76-85

Kelso JE, Entrekin SA (2018) Intermittent and perennial macroinvertebrate communities had similar richness but differed in species traits composition depending on flow duration. Hydrobiologia 807:189-206. 10.1007/s10750-017-3393-y

Lehotský M, Pastuchová Z, Bulánková E, Kokavec I (2016) Testing for longitudinal zonation of macroinvertebrate fauna along a small upland headwater stream in two seasons. Biologia 71(5):574-582

Leibowitz SG, Wigington PJ Jr, Schofield KA, Alexander LC, Vanderhoof MK, Golden HE (2018) Connectivity of streams and wetlands to downstream waters: an integrated systems framework. JAWRA J Am Water Resour Assoc 54(2):298-322 [PubMed: 30078985]

Lenat DR, Resh VH (2001) Taxonomy and stream ecology - the benefits of genus-and species-level identifications. J N Am Benthol Soc 20(2):287-298

MacDonald LH, Coe D (2007) Influence of headwater streams on downstream reaches in forested areas. For Sci 53(2):148-168

McCune B, Grace JB (2002) Analysis of ecological communities. MjM Software, Gleneden Beach.

Meyer JL, Strayer DL, Wallace JB, Eggert SL, Helfman GS, Leonard NE (2007) The contribution of headwater streams to biodiversity in river networks. J Am Water Resour Assoc 43:86-103

National Oceanic and Atmospheric Administration (NOAA) National Centers for Environmental Information (NCEI) (2020) Data Tools: 1981-2010 Normals. https://www.ncdc.noaa.gov/cdo-web/ datatools/normals Accessed 19 October 2020

North Carolina Division of Water Quality (NCDWQ) (2010) Methodology for identification of intermittent and perennial streams and their origins, version 4.11. North Carolina Department of Environment and Natural Resources, Division of Water Quality, Raleigh, NC

Ohio Environmental Protection Agency (OEPA) (2018) Field Evaluation Manual for Ohio's Primary Headwater Habitat Streams, version 4.0. Ohio Environmental Protection Agency, Division of Surface Water https://www.epa.state.oh.us/Portals/35/rules/ PHWHManual_2018_Ver_4\%200_10-22-18.pdf

Paybins KS (2003) Flow origin, drainage area, and hydrologic characteristics for headwater streams in the mountaintop coal-mining region of southern West Virginia. Water Resources Investigation Report 02-4300. USGS, Charleston, WV. https://pubs.usgs.gov/wri/wri02-4300/pdf/ wri02-4300.book.pdf

Pařil P, Leigh C, Polášek M, Sarremejane R, Řezníčková P, Dostálová A, Stubbington R (2019) Shortterm streambed drying events alter amphipod population structure in a central European stream. Fundam Appl Limnol 193(1):51-64

Peel MC, Finlayson BL, McMahon TA (2007) Updated world map of the Köppen-Geiger climate classification Hydrol. Earth Syst Sci 11:1633-1644

Poff NL (1997) Landscape filters and species traits: towards mechanistic understanding and prediction in stream ecology. J N Am Benthol Soc 16(2):391-409

Poff NL, Olden JD, Vieira NK, Finn DS, Simmons MP, Kondratieff BC (2006) Functional trait niches of North American Lotic insects: traits-based ecological applications in light of phylogenetic relationships. J N Am Benthol Soc 25(4):730-755

Aquat Ecol. Author manuscript; available in PMC 2021 October 27. 
R Development Core Team, 2019. R: A language and environment for statistical computing. Version 3.6.0. Vienna, Austria: R Foundation for Statistical Computing. Retrieved from https://www.rproject.org

Robson B, Chester E, Austin C (2011) Why life history information matters: drought refuges and macroinvertebrate persistence in non-perennial streams subject to a drier climate. Mar Freshw Res 62:801-810

Santos AN, Stevenson RD (2011) Comparison of macroinvertebrate diversity and community structure among perennial and non-perennial headwater streams. Northeast Nat 18(1):7-26

Schofield KA, Alexander LC, Ridley CE, Vanderhoof MK, Fritz KM, Autrey BC, DeMeester JE, Kepner WG, Lane CR, Leibowitz SG, Pollard AI (2018) Biota connect aquatic habitats throughout freshwater ecosystem mosaics. J Am Water Resour Assoc 54(2):372-399 [PubMed: 31296983]

Sharpe CFS (1938) Landslides and related phenomena: a study of mass-movements of soil and rock. Columbia University Press, New York, p 137

Shultz RA (1988) Ground-water hydrology of Marshall County, West Virginia, with emphasis on the effects of longwall-coal mining: U.S. Geological Survey Water-Resources Investigations Report 88-4006. $147 \mathrm{p}$

Soria M, Leigh C, Datry T, Bini LM, Bonada N (2017) Biodiversity in perennial and intermittent rivers: a meta-analysis. Oikos 126(8):1078-1089

Storey RG, Quinn JM (2013) Survival of aquatic invertebrates in dry bed sediments of intermittent streams: temperature tolerances and implications for riparian management. Freshw Sci 32(1):250266

Straka M, Polášek M, Syrovátka V, Stubbington R, Zahrádková S, Němejcová D,Šikulová L, Řezníčková P, Opatřilová L, Datry T, Pařil P (2019) Recognition of stream drying based on benthic macroinvertebrates: a new tool in Central Europe. Ecol Ind 106:105486

Straka M, Syrovátka V, Helešic J (2012) Temporal and spatial macroinvertebrate variance compared: crucial role of CPOM in a headwater stream. Hydrobiologia 686:119-134

Stubbington R, Bogan MT, Bonada N, Boulton AJ, Datry T, Leigh C, Vander Vorste R (2017) The biota of intermittent rivers and ephemeral streams: aquatic invertebrates. In: Datry T, Bonada N, Boulton A (eds) Intermittent rivers and ephemeral streams: ecology and management. Elsevier, London, pp 217-243

Stubbington R, Datry T (2013) The macroinvertebrate seedbank promotes community persistence in temporary rivers across climate zones. Freshw Biol 58:1202-1220. 10.1111/fwb.12121

Sweeney BW (1984) Factors influencing life-history patterns of aquatic insects. In: Resh V, Rosenberg D (eds) The ecology of aquatic insects. Praeger Scientific Publishers, NY, pp 56-100

Thornton PE, Thornton MM, Mayer BW, Wei Y, Devarakonda R, Vose RS, Cook RB (2018) Daymet: Daily Surface Weather Data on a 1-km Grid for North America, Version 3. ORNL DAAC, Oak Ridge, Tennessee, USA. 10.3334/ORNLDAAC/1328

Vieira NK, Poff NL, Carlisle DM, Moulton SR, Koski ML, Kondratieff BC (2006) A database of lotic invertebrate traits for North America. US Geol Survey Data Series 187:1-15

WVDEP (2021) West Virginia water quality standards. WV Department of Environmental Protection, Charleston, WV. https://dep.wv.gov/WWE/getinvolved/sos/Documents/WQS/Standards.pdf

Walters AW (2011) Resistance of aquatic insects to a low-flow disturbance: exploring a trait-based approach. J N Am Benthol Soc 30(2):346-356

Wigington PJ, Moser TJ, Lindeman DR (2005) Stream network expansion: a riparian water quality factor. Hydrol Proc 19:1715-1721

Williams DD (1996) Environmental constraints in temporary fresh waters and their consequences for the insect fauna. J N Am Benthol Soc 15(4):634-650

Williams DD (2016) Invertebrates in groundwater springs and seeps. In: Batzer D, Boix D (eds) Invertebrates in freshwater wetlands: an international perspective on their ecology. Springer, Cham, pp 357-409

Wipfli MS, Richardson JS, Naiman RJ (2007) Ecological linkages between headwaters and downstream ecosystems: Transport of organic matter, invertebrates, and wood down headwater channels. J Am Water Resour Assoc 43(1):72-85

Wohl E (2017) The significance of small streams. Front Earth Sci 11(3):447-456 
Woods AJ, Omernik JM, Brown DD, Kiilsgaard CW (1996) Level III and IV Ecoregions of Pennsylvania and the Blue Ridge Mountains, the Ridge and Valley, and the Central Appalachians of Virginia, West Virginia, and Maryland EPA/600R-96/077. USEPA, ORD, Corvallis, OR 


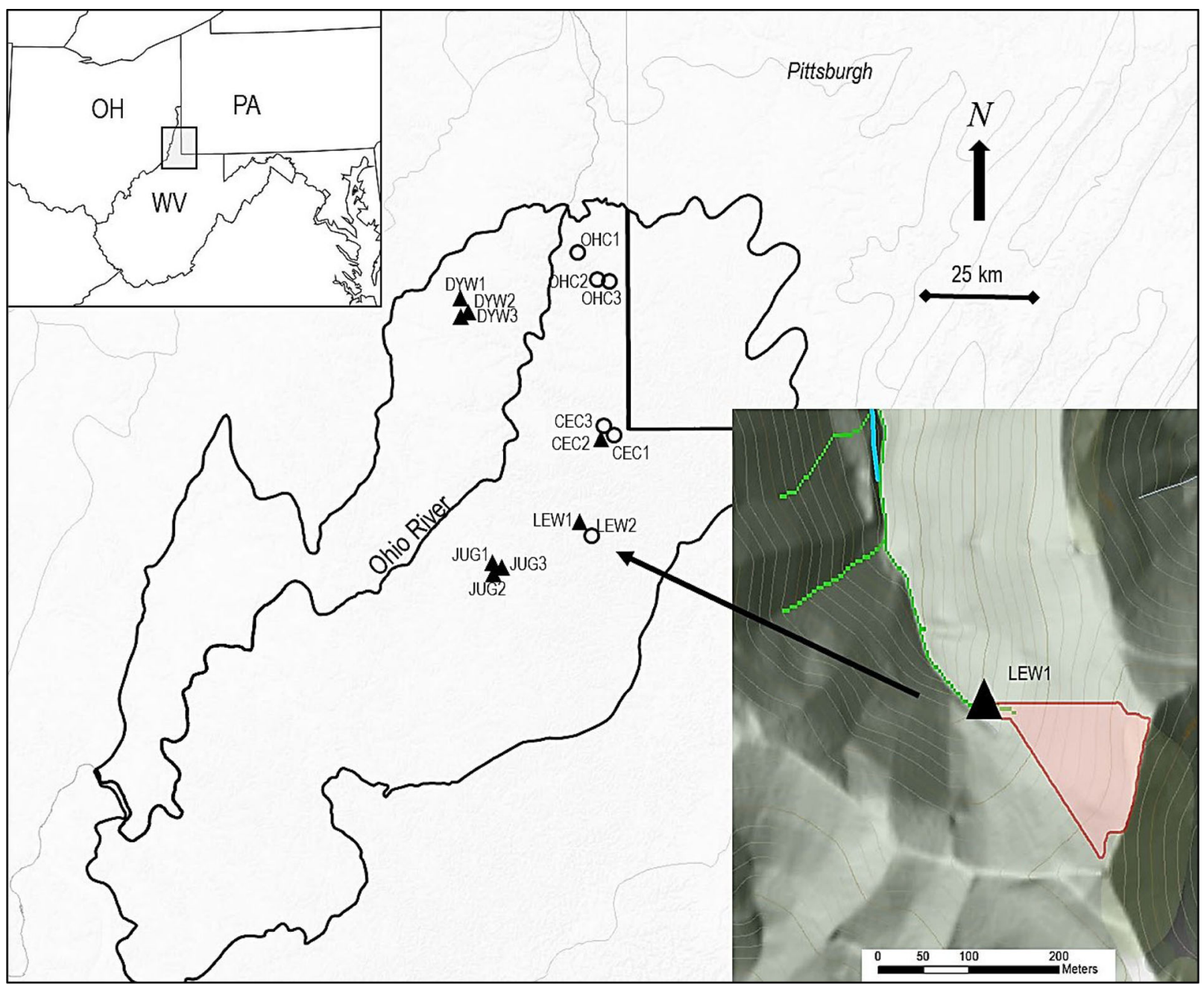

Fig. 1.

Location map of the 14 study sites. Dark outlined area encompasses the Permian Hills subecoregion spanning Ohio, West Virginia, and Pennsylvania. Triangles and circles represent intermittent and perennial sites, respectively. Insert map shows example catchment and sample point (LEW1) where the thicker blue line indicates the NHD flowline; thinner green lines represent streams based on flow accumulation grid $(1 \mathrm{~m})$ delineation (see text) 


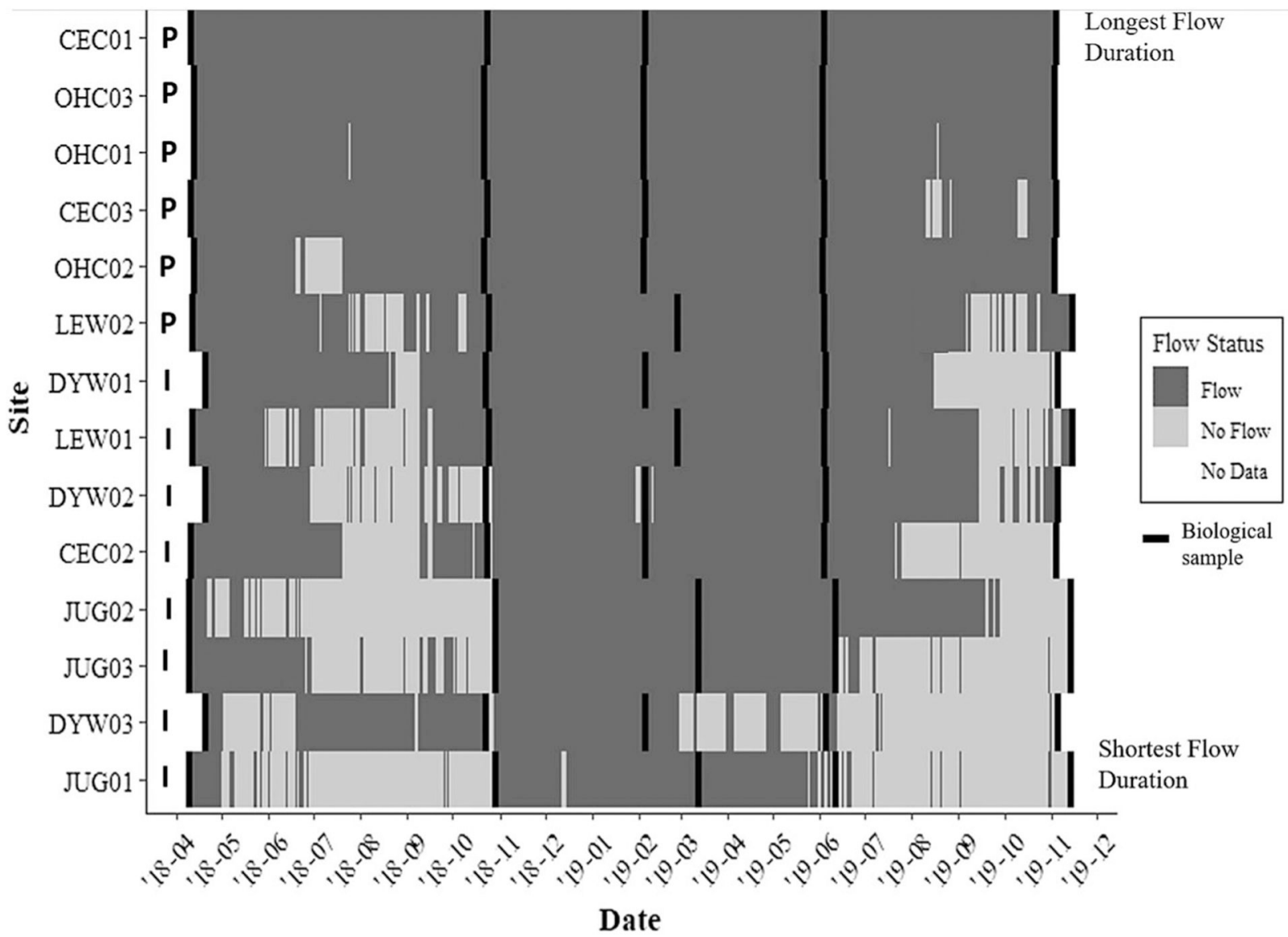

Fig. 2.

Flow duration of the 14 sites over the 19-month study period (year and month on $\mathrm{x}$-axis). Perennial $(P)$ and intermittent (I) sites are ordered top to bottom by flow duration with macroinvertebrate sample times denoted as vertical black lines 

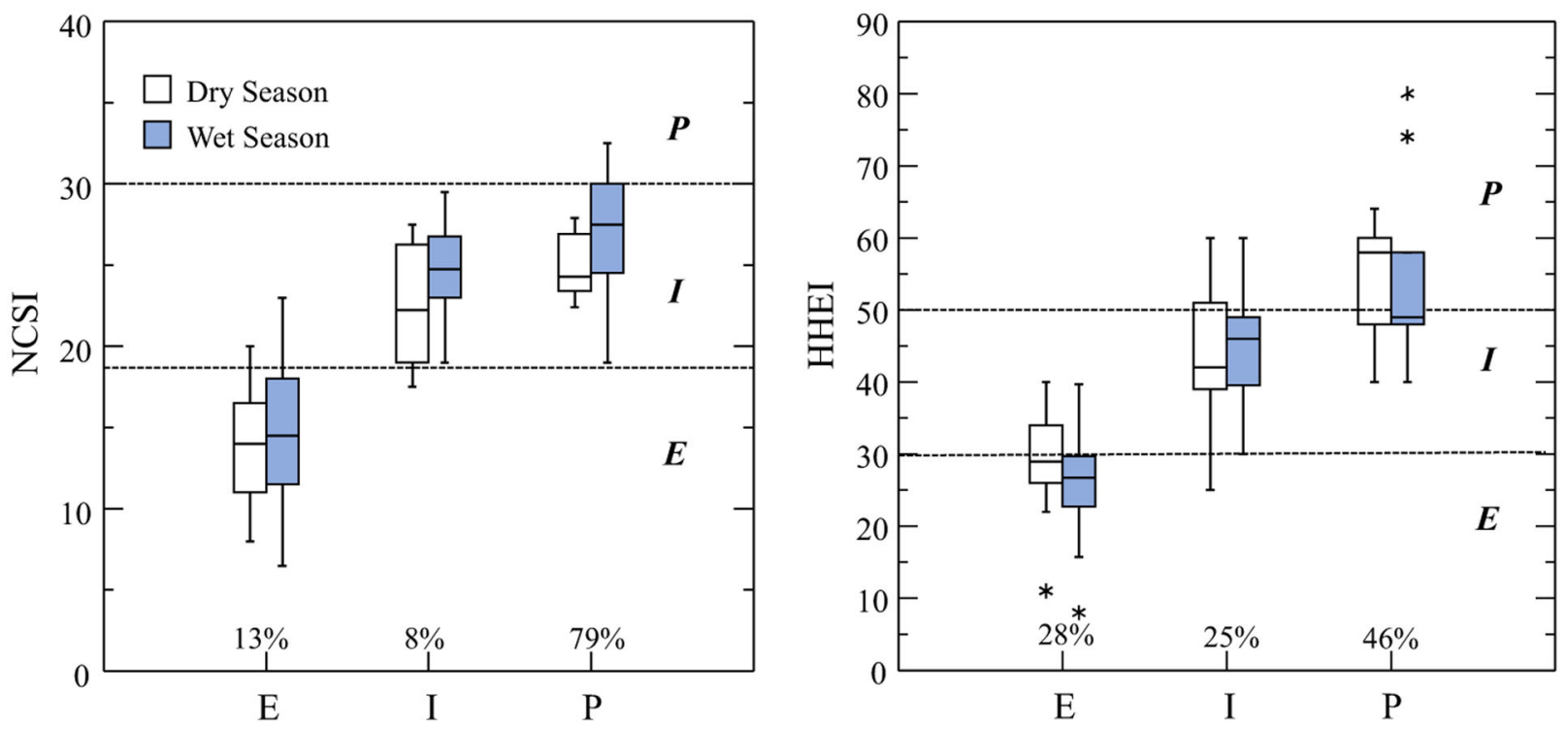

Fig. 3.

Box (median and interquartile range) and whisker (non-outlier range) plots of NCSI and HHEI scores between ephemeral $(E, n=21)$, intermittent $(I, n=24)$, and perennial $(P, n=$ 18) streams during wet (April 2018, Feb 2019) and dry (Oct 2018) seasons showing overall misclassification rate $(\%)$. Asterisks represent outlier values. Horizontal lines represent set point thresholds for $E, I$, and $P$ classification based on NC and $\mathrm{OH}$ protocols. NCSI and HHEI were not assessed in June or November 2019 

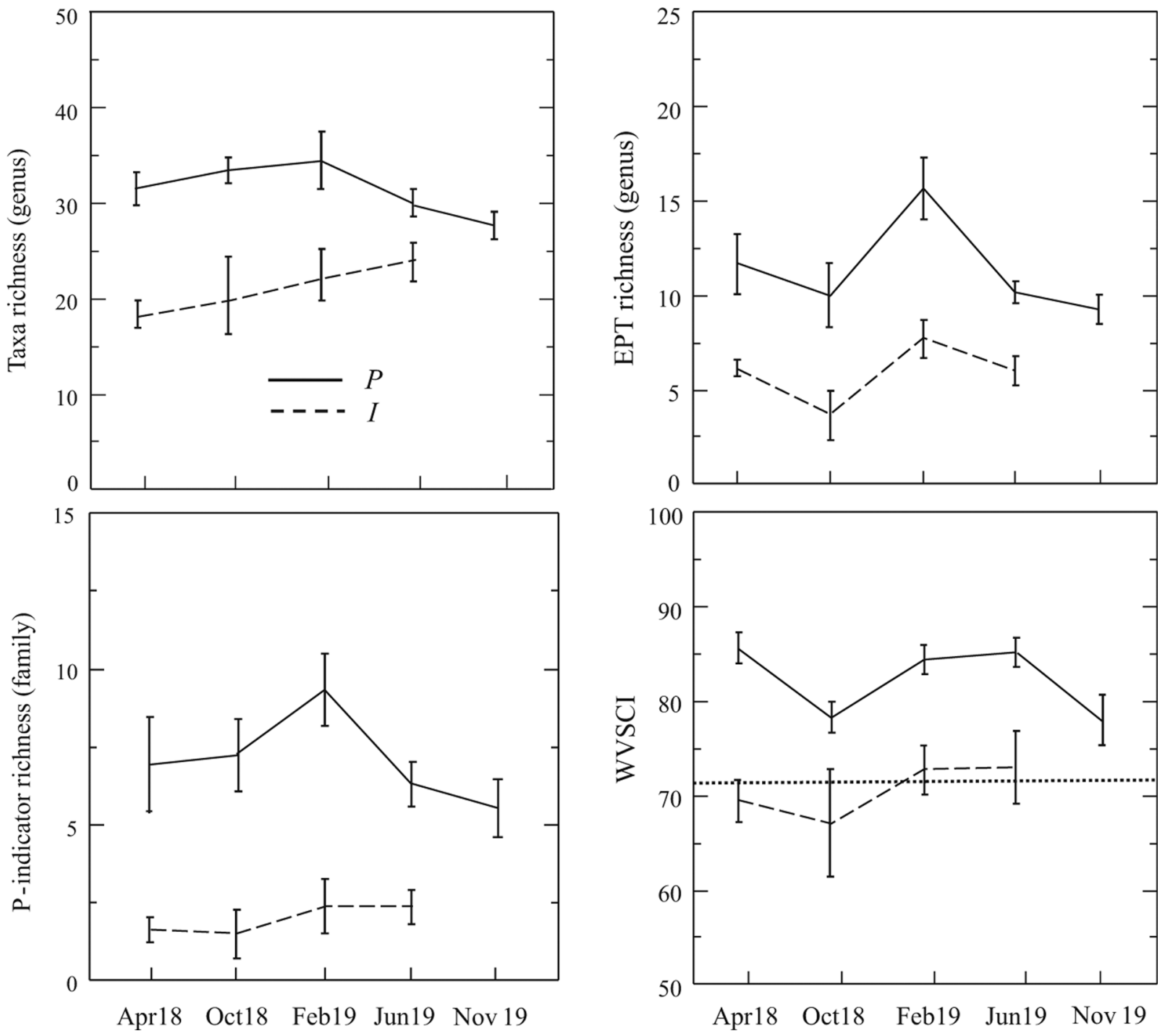

Fig. 4.

Mean $( \pm$ SE) macroinvertebrate metric values among monthly samples in intermittent (I) and perennial $(P)$ streams. In Nov 2019, I sites were dry and no samples were collected. Horizontal line in WVSCI plot indicates the attainment-impairment threshold adopted by the state of WV 

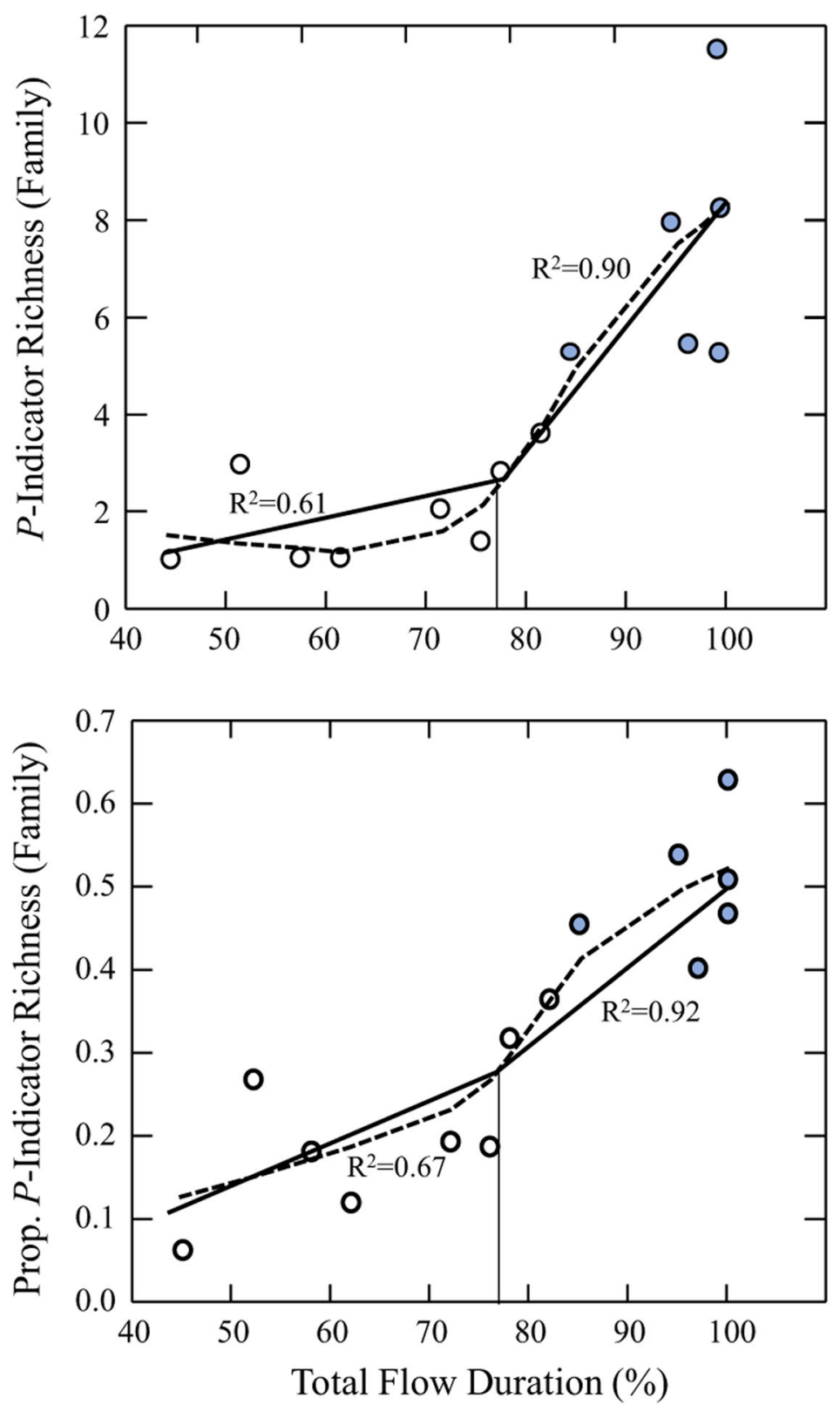

Fig. 5.

Mean family-level perennial $(P)$ indicator richness $(\mathrm{A})$ and proportional $P$-indicator richness (B) values along total flow duration gradient (\% of total record $=19$ months) grouped by flow classes. LOWESS curve fit (dashed line) and segmented (piecewise) linear regression fit (solid line) with segmented $R^{2}$ shown. The vertical lines represent the changepoints in the relationship from piecewise regression 


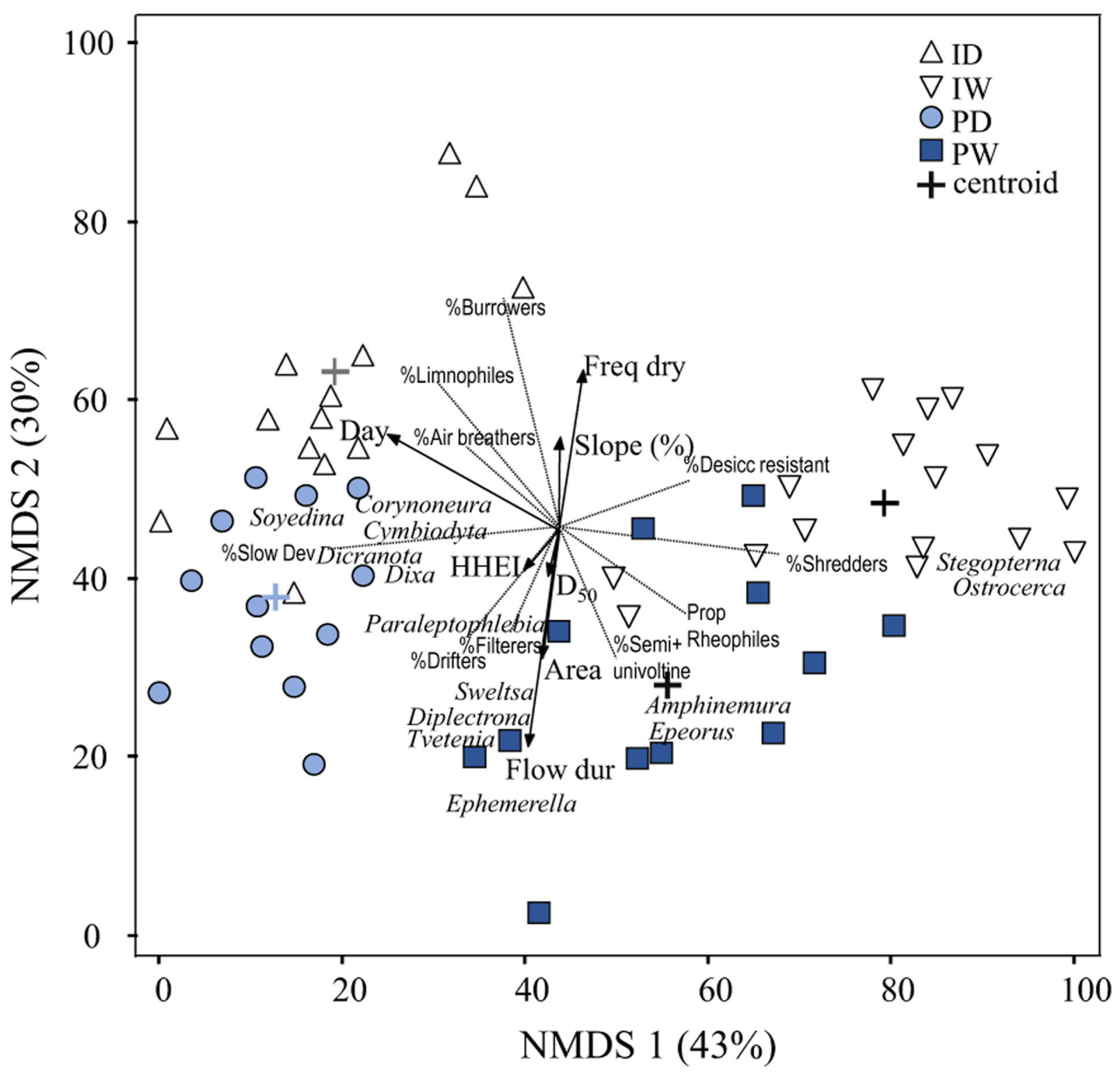

Fig. 6.

Non-metric multidimensional scaling ordination of macroinvertebrate assemblages grouped by intermittent-dry (ID), intermittent-wet (IW), perennial-dry (PD), and perennial-wet (PW) flow and season classes with " + " denoting multivariate group centroids. Percent variation explained by each axis in parentheses. Vectors of environmental variables and traits with $r>$ 0.4 plotted. For clarity, only genera with $r>0.6$ are plotted 


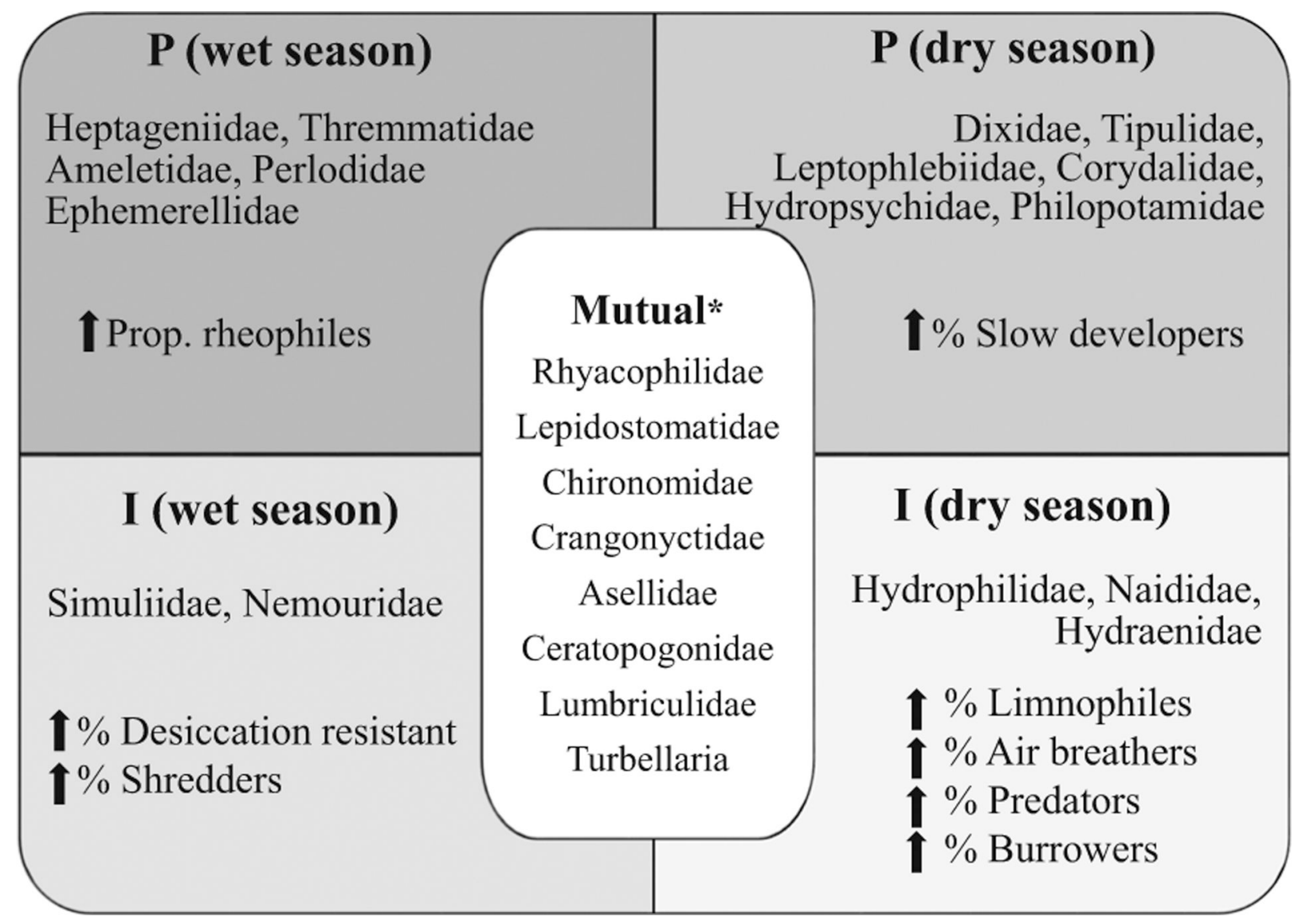

Fig. 7.

Matrix of taxonomic and trait signatures among perennial (P) and intermittent (I) flow classes during winter-spring (wet season) and summer-fall (dry season). Family lists based on indicator species analysis (ISA; $a=0.05$ ) between the four groups; $a$ relaxed to $<0.1$ for $I$ classes (sorted in order of decreasing significance). Trait direction arrows indicate relative increase within classes based on exploratory box plots and nonparametric pairwise tests (see online resource 9). *Mutually occurring non-significant $(p>0.5)$ indicator value taxa with similar relative frequencies among flow classes 


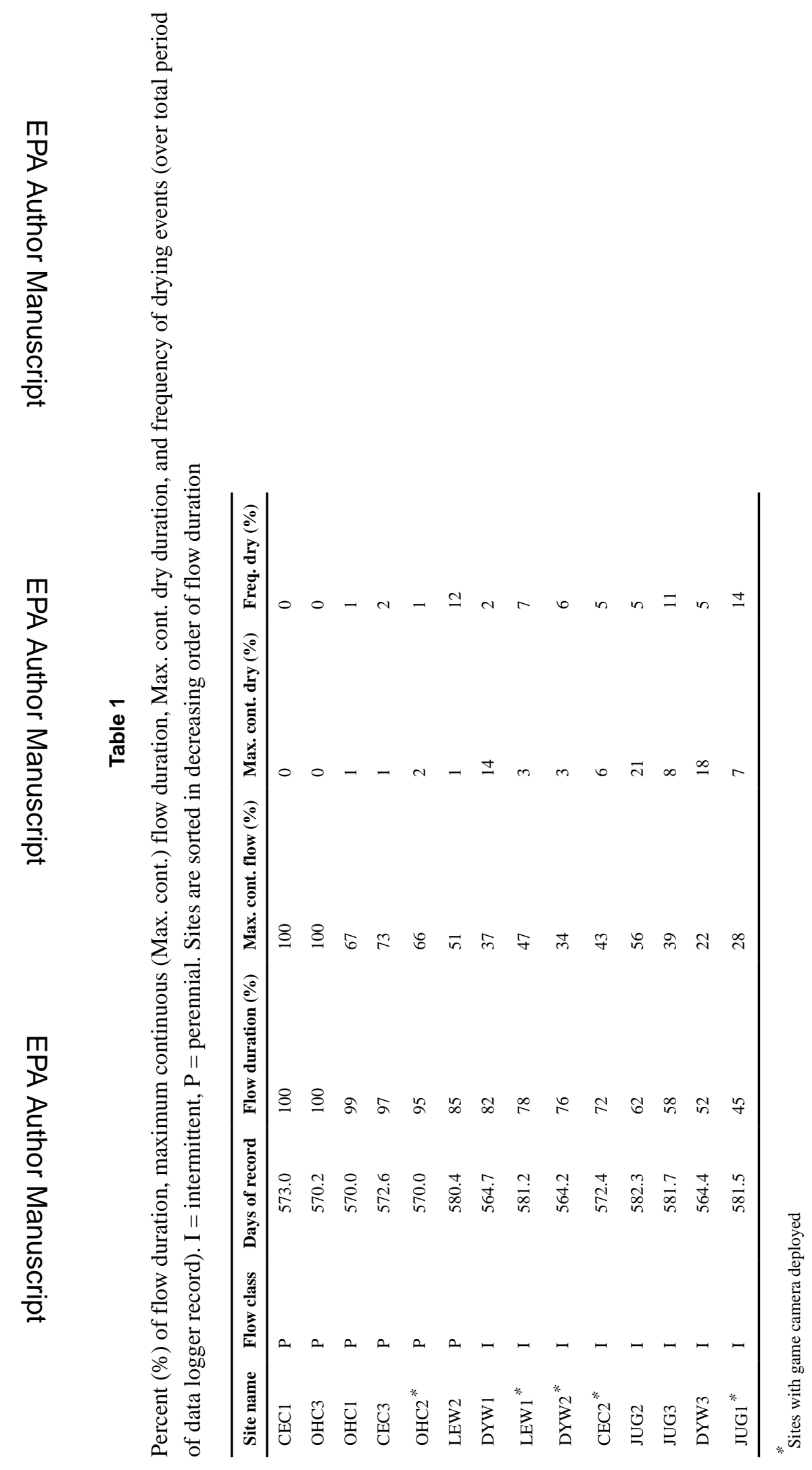

Aquat Ecol. Author manuscript; available in PMC 2021 October 27. 


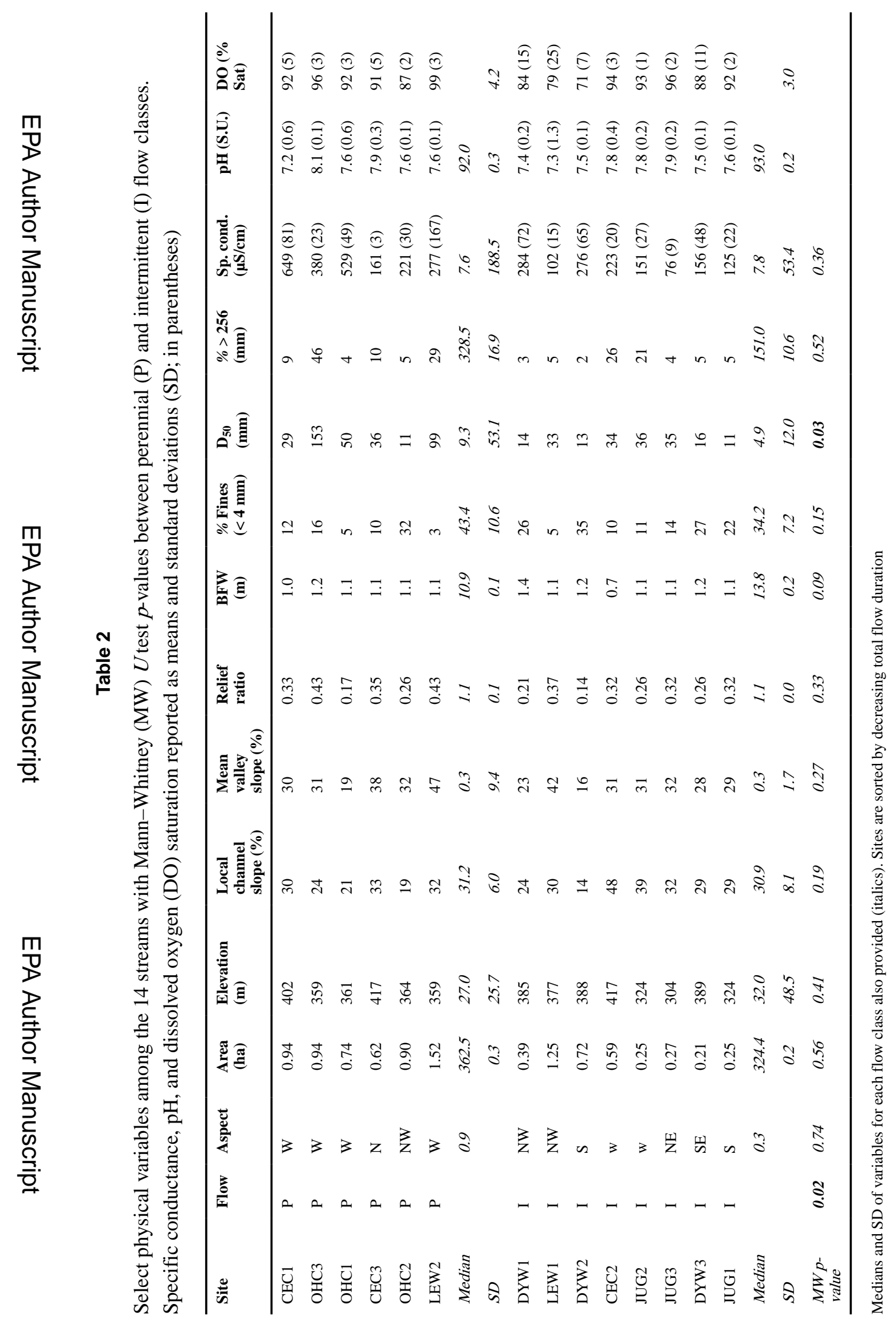




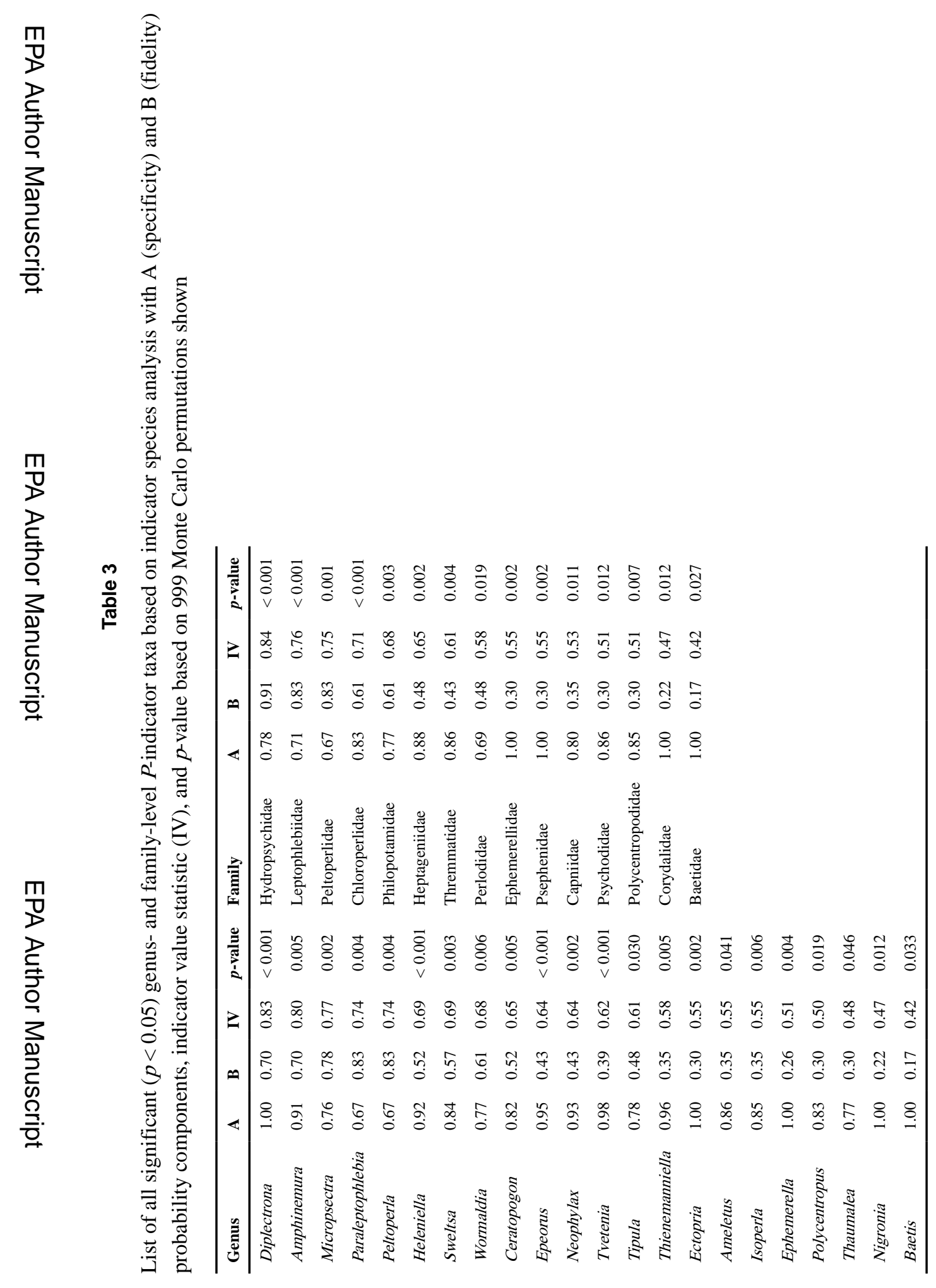




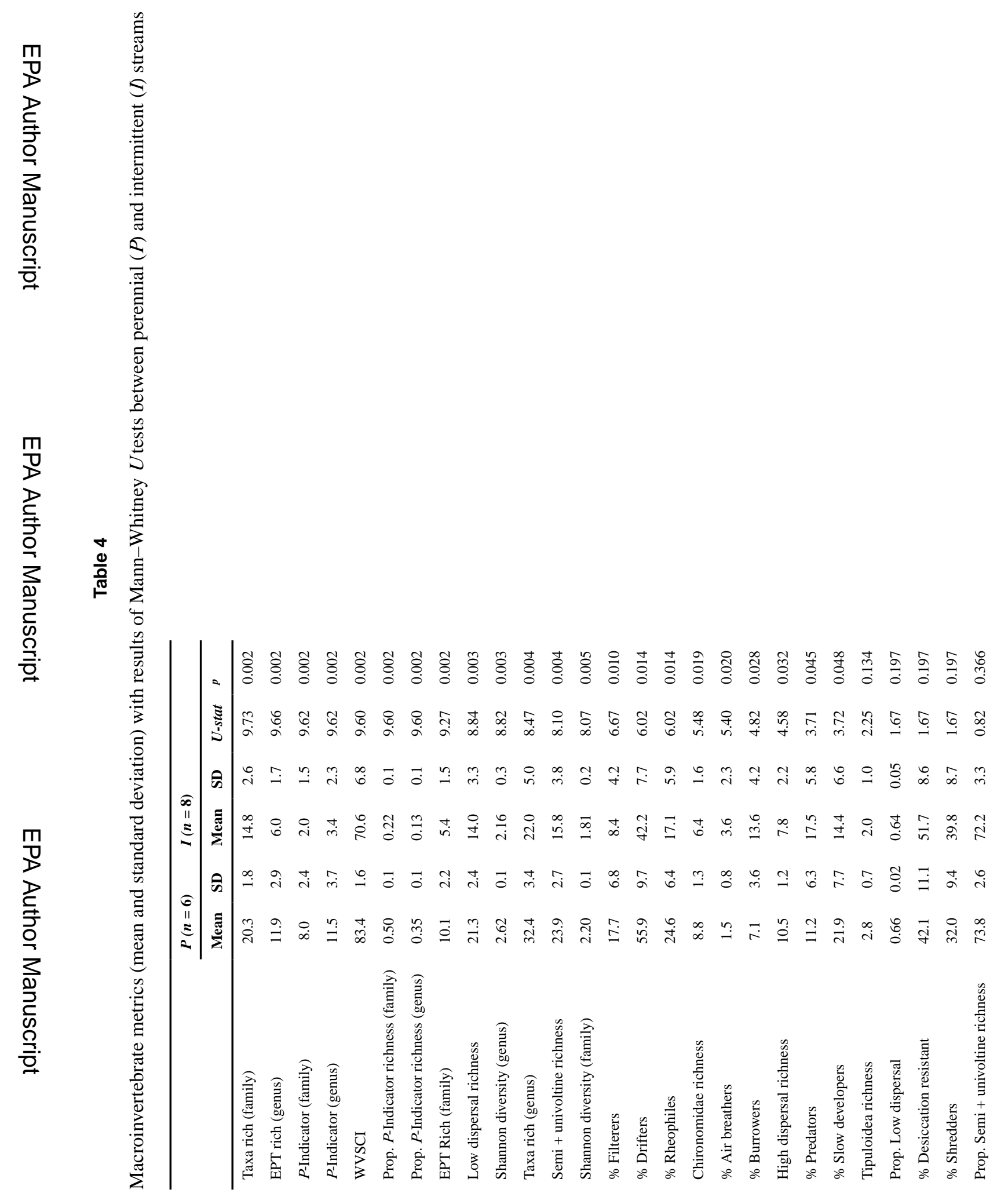


Pond et al.

Page 34

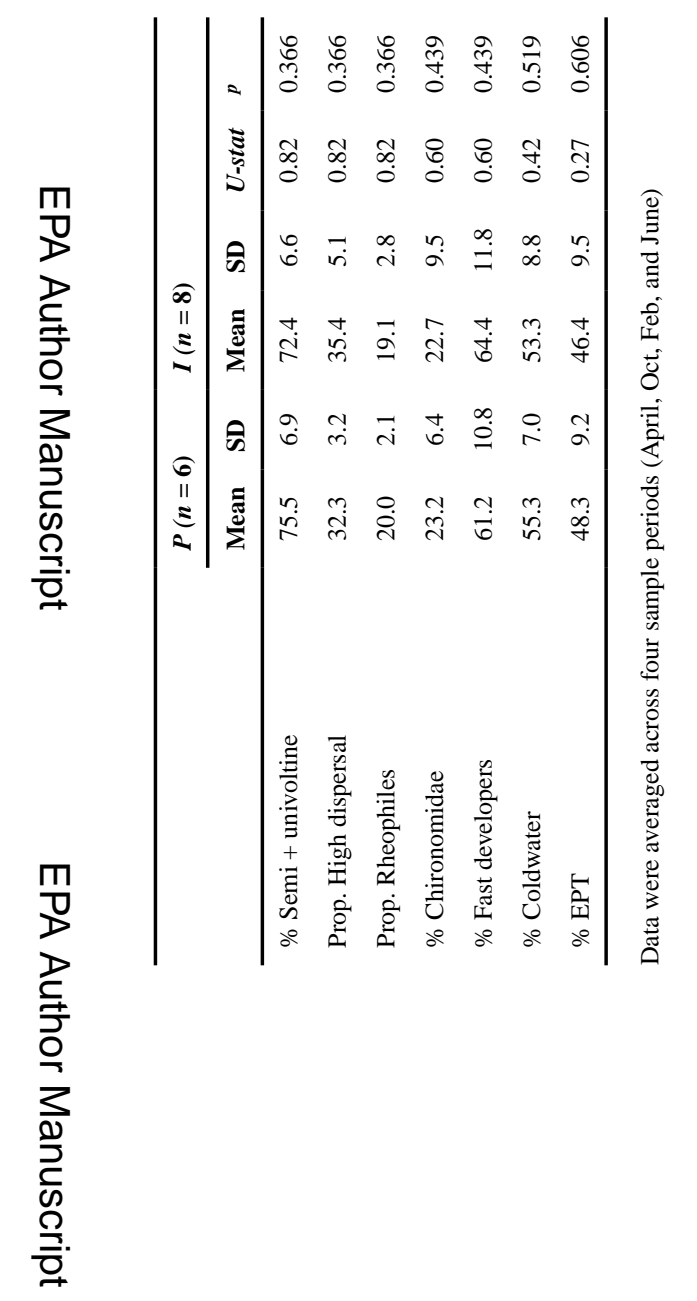

m

Aquat Ecol. Author manuscript; available in PMC 2021 October 27. 
